\title{
Detecting climate signals in populations across life histories
}

\author{
Stéphanie Jenouvrier ${ }^{1}$ (]) | Matthew C. Long ${ }^{2}$ | Christophe F. D. Coste ${ }^{3}$ (1) |

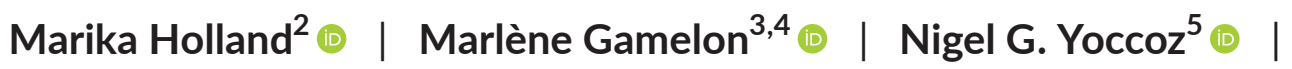 \\ Bernt-Erik Sæther ${ }^{3}$ (
}

\author{
${ }^{1}$ Biology Department, Woods Hole \\ Oceanographic Institution, Woods Hole, \\ Massachusetts, USA \\ ${ }^{2}$ National Center for Atmospheric \\ Research, Boulder, Colorado, USA \\ ${ }^{3}$ Centre for Biodiversity Dynamics, \\ Department of Biology, Norwegian \\ University of Science and Technology, \\ Trondheim, Norway \\ ${ }^{4}$ Laboratoire de Biométrie et Biologie \\ Évolutive, CNRS, Unité Mixte de \\ Recherche (UMR) 5558, Université Lyon 1 , \\ Université de Lyon, Villeurbanne, France \\ ${ }^{5}$ Department of Arctic and Marine \\ Biology, UiT The Arctic University of \\ Norway, Tromsø, Norway

\section{Correspondence} \\ Stéphanie Jenouvrier, Woods Hole \\ Oceanographic Institution, 266 Woods \\ Hole Road, Woods Hole, MA 02543-1050, \\ USA. \\ Email: sjenouvrier@whoi.edu

\section{Funding information} \\ NSF, Grant/Award Number: OPP 1744794 \\ and OPP 2037561; Institute Paul Emile \\ Victor; Terres Australes et Antarctiques \\ Françaises; NASA, Grant/Award Number: \\ 8ONSSC20K1289
}

\begin{abstract}
Climate impacts are not always easily discerned in wild populations as detecting climate change signals in populations is challenged by stochastic noise associated with natural climate variability, variability in biotic and abiotic processes, and observation error in demographic rates. Detection of the impact of climate change on populations requires making a formal distinction between signals in the population associated with long-term climate trends from those generated by stochastic noise. The time of emergence (ToE) identifies when the signal of anthropogenic climate change can be quantitatively distinguished from natural climate variability. This concept has been applied extensively in the climate sciences, but has not been explored in the context of population dynamics. Here, we outline an approach to detecting climatedriven signals in populations based on an assessment of when climate change drives population dynamics beyond the envelope characteristic of stochastic variations in an unperturbed state. Specifically, we present a theoretical assessment of the time of emergence of climate-driven signals in population dynamics $\left(\mathrm{ToE}_{\mathrm{pop}}\right)$. We identify the dependence of $\mathrm{ToE}_{\mathrm{pop}}$ on the magnitude of both trends and variability in climate and also explore the effect of intrinsic demographic controls on $\mathrm{ToE}_{\mathrm{pop}}$. We demonstrate that different life histories (fast species vs. slow species), demographic processes (survival, reproduction), and the relationships between climate and demographic rates yield population dynamics that filter climate trends and variability differently. We illustrate empirically how to detect the point in time when anthropogenic signals in populations emerge from stochastic noise for a species threatened by climate change: the emperor penguin. Finally, we propose six testable hypotheses and a road map for future research.
\end{abstract}

\section{KEYWORDS}

climate change, emperor penguin, life histories, population trend, population variability, signal to noise, time of emergence 


\section{1 | INTRODUCTION}

Climate change is expected to have significant effects on biological populations (Mason et al., 2019). Many studies have assessed the influence of particular climate variables on demographic rates (e.g., survival) and population sizes (e.g., see review Gaillard et al., 2013; Jenouvrier, 2013; Reed et al., 2021). However, while the primacy of climate influence is commonly accepted, specific detection and attribution of population trends to anthropogenic changes in climate is complicated by substantial stochastic noise related to observation error (i.e., errors due to measurement imprecision) and process error in biological processes (i.e., unexplained variation in true abundance driven by unobserved biotic such as species interactions or abiotic processes such as habitat quality, resource variability, etc.), and climate variability (Che-Castaldo et al., 2017; Parmesan et al., 2013; Table 1). Climate variability is an important characteristic of the climate system and a driver of population dynamics (Boyce et al., 2006; Vázquez et al., 2015) that may occlude the population response to the underlying climate change signal.

Natural climate variability is a noise from unforced variability generated internally within the climate system (Mann et al., 2021; Table 1). Natural variability in the climate system occurs over a broad range of temporal and spatial scales, with spectral properties in the seasonal, inter-annual to decadal bands. It arises from different sources, including variations that are (1) driven by a periodic external forcing, like the diurnal or the seasonal cycle of insolation, (2) due to the nonlinear interplay of feedbacks within the climate system, such as coupled mode of variability (e.g., El Niño-Southern Oscillation, North Atlantic Oscillation, Pacific Decadal Oscillation), and (3) associated with random fluctuations in the external or internal climate system (Ghil, 2002). In addition, climate change is characterized by an anthropogenic climate change signal (Table 1). This secular trend is the deterministic response of the climate system to an external forcing driven by anthropogenic emissions of greenhouse gases and changes in land use. Hence, the detection of anthropogenic forced change is a signal to noise problem.

To detect and attribute the threats to a species posed by climate, climate-driven signals in population should be distinguished from stochastic noise. The concept of time of emergence (ToE) exactly does that: it identifies when the signal of anthropogenic climate change can be formally distinguished from noise associated with natural variability (Table 1 ). In climate science, the ToE has been studied extensively (Hawkins et al., 2020; Hawkins \& Sutton, 2012). It is used to detect climatic changes and to describe whether climate changes are potentially beyond the known natural environmental variability of ecosystems (Giorgi \& Bi, 2009; Mahlstein et al., 2013).

Although this concept of ToE has yet to be formally applied to ecological time series, some studies have quantified when novel climate conditions relevant for ecological processes will emerge from natural variability. For example, Beaumont et al. (2011) have characterized the standard deviation (SD) of surface air temperature for a baseline period (1961-1990) and then evaluated the number
TAB LE 1 Glossary adapted from the IPCC definitions (IPCC et al., 2018)

\section{Climate change}

Change in the state of the climate that can be identified (e.g., using statistical tests) by changes in the mean and/or the variability of its properties and that persists for an extended period, typically decades or longer. Climate change may be due to natural internal processes or external forcings such as modulations of the solar cycles, volcanic eruptions, and persistent anthropogenic changes in the composition of the atmosphere or in land use.

Climate model

A numerical representation of the climate system based on the physical, chemical, and biological properties of its components, their interactions and feedback processes, and accounting for some of its known properties. Climate models have structural differences for example, in their spatial resolution, complexity of parameterizations, and processes that are explicitly represented.

\section{Climate signal}

Variations in the state of the climate system that have an identifiable and statistically discernible structure in time and/or space, such as a long-term warming trend.

\section{Climate simulation}

A model simulation of the climate state. This can include the simulated response of the climate system to characterize historical climate conditions, climate predictions, or climate projections.

Climate projection

A simulated response of the climate system to a forcing scenario of future emission or concentration of greenhouse gases (GHGs) and aerosols, generally derived using climate models.

Climate variability

Variations in the mean state and other statistics (such as standard deviations, the occurrence of extremes, etc.) of the climate on all spatial and temporal scales beyond that of individual weather events. Variability may be due to natural internal processes within the climate system (internal variability), or to variations in natural or anthropogenic external forcing (external variability).

Natural climate variability

Climate fluctuations from unforced variability generated internally within the climate system (e.g., weather) or associated with external forces to the climate system (e.g., volcanoes).

(Model) Ensemble

A group of parallel model climate simulations. Ensembles made with the same model but different initial conditions characterize the simulation uncertainty associated with internal climate variability, whereas multimodel ensembles including simulations by several models also include the impact of model differences.

Time of emergence

The time at which the signal of climate change emerges from the noise of natural climate variability.

Emergence threshold

A threshold at which climate change is consider to emerge.

of months that the temperature exceeds 2 SDs by 2070 for various ecoregions of exceptional biodiversity. They found that more than $83 \%$ of terrestrial and freshwater ecoregions will be exposed to temperature exceeding 2 SDs by 2070. 
The ToE explicitly characterizes the point in time when anthropogenic climate change can be formally distinguished from noise associated with natural variability. Hence, it informs on how fast changes exceed natural variability and can help prioritize decisions about when, where, and for which conservation and management actions may be necessary. Some studies have characterized explicitly the ToE of ecosystem drivers in marine ecosystems (Henson et al., 2017; Schlunegger et al., 2020). For example, Henson et al. (2017) found that climate change signals of $\mathrm{pH}$ and SST emerge rapidly while climate change trends in interior oxygen content and primary productivity emerge later. In terrestrial ecosystems, Rojas et al. (2019) focused on the timing when the precipitation changes will emerge outside the range of natural variability during the 21th century relevant for agricultural activities. They found early timing of emergence in precipitation trends for the production regions of four major crops (wheat, soybean, rice, and maize) even under a lowemission scenario. Sorte et al. (2019) characterized the seasonal and spatial variations in the emergence of novel climates characterized by precipitation, minimum and maximum temperature, along the migration routes of 77 passerine bird species. They found that earlier ToE occurs for migrants that winter within the tropics. However, none of these studies have applied directly the concept of ToE to time series of population dynamics.

Here, we apply the concept of ToE to characterize climate-driven signals in population dynamics. We present a new perspective on detecting climate-related impacts in populations by characterizing the $\mathrm{ToE}$ in population growth rate (hereafter, $\mathrm{ToE}_{\mathrm{pop}}$ ), the point in time when climate-driven signals in population dynamics can be quantitatively distinguished from noise associated with year-specific stochastic variations in population growth rates (Figure 1). While in climate science, the noise is associated with climate natural variability, applying this approach to population dynamics does not exclude other sources of noise (e.g., observation and process errors; demographic and environmental variability, the latter being driven by fluctuations in physical habitat, resource availability, and biological interactions).

For species threatened by climate change, $\mathrm{ToE}_{\mathrm{pop}}$ can represent the time at which the population will detectably decline to a level below its historical variability. This point in time potentially corresponds to the time at which the species will be exposed to high extinction risk, to the time at which individuals will migrate massively to track ecological niches, or to the time at which individuals may have to adapt to new conditions through evolutionary adaptations. The earlier the $\mathrm{ToE}_{\mathrm{pop}}$ occurs, the faster novel conditions emerge out of the natural range of variability, the faster the population will reach a non-historical level, with less time for the organisms to adapt or migrate. The $\mathrm{ToE}_{\text {pop }}$ is one illustrative metric that acknowledges the dual role of natural variability and an anthropogenic climate change signal, also useful for populations increasing under climate change (Román-Palacios \& Wiens, 2020; Stephens et al., 2016). Importantly, ToE allows meaningful comparative studies of when the signal of



FIGURE 1 Conceptual diagram of the time of emergence (ToE) in climate ( $\left.\mathrm{ToE}_{\text {climate }}\right)$ and in populations (ToE $\left.\mathrm{E}_{\mathrm{pop}}\right)$. ToE identifies the point in time when the signal of anthropogenic climate change (red time series) emerges from the noise associated with natural variability (black time series). $\mathrm{ToE}_{\mathrm{pop}}$ depends on the response of population growth rate to climate that is defined by (1) the impact of climate on demographic rates (e.g., survival) with different functional forms that influence the sensitivity of demographic rates to climate; (2) the impact of demographic rates on the population growth rate resulting from nonlinear demographic processes occurring throughout the species life cycle (described in section Population projections) 
anthropogenic climate change emerges from natural variability across ecosystem drivers (Henson et al., 2017), species (Sorte et al., 2019), ecosystems (Beaumont et al., 2011), and for future socioeconomic processes relevant for climate mitigation (Schlunegger et al., 2020).

From a conceptual viewpoint, $\mathrm{ToE}_{\mathrm{pop}}$ occurs earlier when the slope of the population climate-driven trend is large and/or when the population variability is small (Figure 1). Both the population climatedriven trend and variability depend on the species' life history and the functional relationships between climate and the demographic rates (Barraquand \& Yoccoz, 2013). Specifically, species of both plant and animal kingdoms can be ranked along a main axis of lifehistory variation, the so-called "slow-fast continuum" (Gaillard et al., 2016; Oli, 2004; Sæther, 1987; Salguero-Gómez et al., 2016; Stearns, 1983). Species with fast life history are characterized by early maturity, high reproductive output, and short lifespan; while species with slow life history have opposite characteristics. Previous work has shown that depending on their position along this continuum, species exhibit contrasting demographic responses to climate change with various spectrum of variability and amplitude of the response (Compagnoni et al., 2021; Doak \& Morris, 2010; Jenouvrier et al., 2005; Morris et al., 2008; Paniw et al., 2017). In addition, the population responses to climate change depend on the function that links climate variables to demographic rates (survival, growth, reproduction) that drive population growth rate and structure (i.e., functional relationships, Figure $\mathrm{S} 1$ ).

After briefly reviewing the time of emergence in climate (Section 2 ), we present this concept in the context of population dynamics (Section 3). Then, we characterize and compare the time of emergence of climate-driven signals in population dynamics in a theoretical context to address five questions (Section 4):

- How does $\mathrm{ToE}_{\mathrm{pop}}$ in populations relate to ToE in climate?

- How does $\mathrm{ToE}_{\text {pop }}$ vary across life histories (e.g., slow-fast species)?

- How does $\mathrm{ToE}_{\text {pop }}$ vary across demographic processes (e.g., survival, reproduction)?

- How does $\mathrm{ToE}_{\mathrm{pop}}$ vary among different functional relationship between climate and demographic rates?

- Do some species, demographic processes, or functional relationship magnify the signal of anthropogenic climate change?

We find that different life histories (e.g., long vs. short-lived species) and demographic processes by which climate affects the population (i.e., through survival, reproduction) provide different "scale-dependent" filters so that some life histories magnify signalto-noise ratios while other demographic dynamics prolong $\mathrm{ToE}_{\mathrm{pop}}$ Furthermore, to illustrate our theoretical results, we quantify the $\mathrm{ToE}_{\mathrm{pop}}$ of an iconic species endangered by climate change: the emperor penguin (Aptenodytes forsteri; Jenouvrier et al., 2021; Section 5). Finally, we propose a set of six testable hypotheses based on the patterns of ToE in climate (hereafter $\mathrm{ToE}_{\text {climate }}$ ) and the demographic processes across life histories and propose a road map for future studies on the $\mathrm{ToE}_{\mathrm{pop}}$ (Section 6).

\section{2 | TIME OF EMERGENCE IN CLIMATE}

The concept of $\mathrm{ToE}_{\text {climate }}$ has been discussed for several decades in the climate sciences with studies attempting to detect the carbon dioxide warming signal published more than 80 years ago (Callendar, 1938; Revelle \& Suess, 1957; see review in Hawkins et al., 2020). The time of emergence has been characterized in temperature (Mahlstein et al., 2011), precipitation (Giorgi \& Bi, 2009), climate extremes (King et al., 2015), in sea level (Lyu et al., 2014), in Arctic climate (Landrum \& Holland, 2020), and biogeochemical variables (e.g., Henson et al., 2017; Long et al., 2016; Schlunegger et al., 2020).

Different methods have been used to quantify $\mathrm{ToE}_{\text {climate, }}$ most of them use climate model simulations (but see Hawkins et al., 2020, for an application using observation of temperature). The common methods for estimating $\mathrm{ToE}_{\text {climate }}$ are the signal threshold method (Section 3), and the signal-to-noise ratio method with a particular cutoff (Hawkins \& Sutton, 2012); a variant of this approach is the identification of the signalto-noise ratio using a predefined threshold across multiple consecutive years (refereed as the exceedance threshold; Mora et al., 2013). Various statistical methods have been developed, from statistical test to assess for significant differences between time periods (Zappa et al., 2015), estimation of the standard error of the regression to estimate the lead time required for a linear trend to emerge from natural variability (Mahlstein et al., 2012), development of hierarchical statistical state-space model (Barnhart et al., 2016), or artificial neural networks (Barnes et al., 2018).

Recently, the availability of large ensembles of climate (or Earth system) models has open new doors to quantify climate natural variability and hence evaluations of the $\mathrm{ToE}_{\text {climate }}$. An ensemble is a collection of coupled climate simulations (Table 1) that are integrated in parallel, typically with small differences in initial conditions applied to each ensemble member. Climate model generates internal variability as a product of interactions between components internal to the climate system (Hasselmann, 1976). Since the climate system is chaotic, perturbations in initial conditions grow with time, randomizing the phase of natural variability and leading to spread across the ensemble. This spread can be interpreted as a measure of the amplitude of natural climate variability. As all the ensemble members are subject to the same external forcing (i.e., emissions scenario), the deterministic response of the climate system can be assessed as the mean across the ensemble members, which effectively filters out the noise associated with natural variability (Kay et al., 2015). Modeling centers usually contribute a small number of ensemble members to international climate change projection assessments, typically ranging from 3 to 10 ensemble members for a given model. Large ensembles with ensemble sizes ranging from 30 to 100 members permit climatologists to compute emergence thresholds to formally consider the uncertainty in the forced response due to natural climate variability (Barnhart et al., 2016).

Here, we use signal threshold method (Section 3) based on a large ensemble by constructing prediction interval of the climate and population projections, and estimate the time taken by the system to emerge from the background of natural variability (Barnhart et al., 2016). For example, the left part of Figure 2 shows an idealized climate trajectory corresponding to a single ensemble member 
Species 1

Time of emergence in climate:

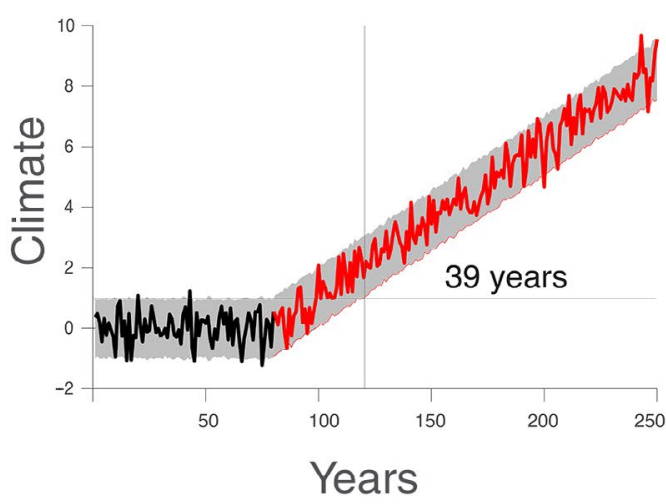

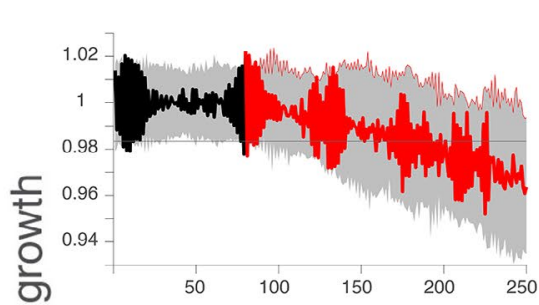

Species 3

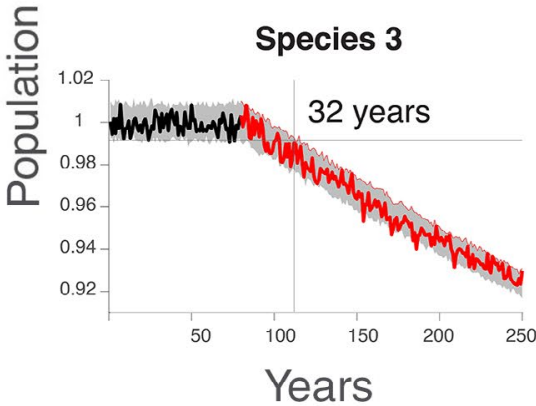

Time of emergence in population:

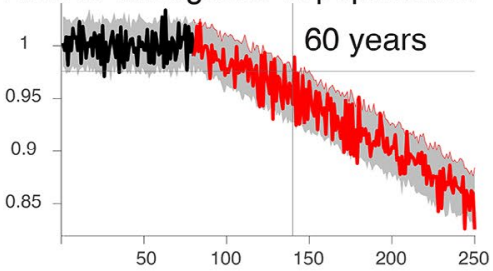

Species 4

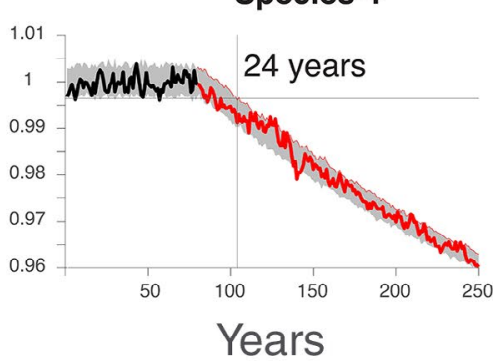

FIGURE 2 Illustrative figure of the time of emergence in climate ( $T_{\mathrm{O}} \mathrm{E}_{\text {climate }}$ on left panel) and in populations (ToE $\mathrm{E}_{\mathrm{pop}}$ on right panels) of four species along the gradient of life histories, from fast species (species 1) to slow species (species 4). The figure shows one time series simulated during the historical environment (black line) and forced environment (red line). The emergence thresholds are based on a 95\% prediction interval of 1000 simulations (grey area). The natural variability in climate is $\sigma=0.5$. The forced perturbation caused by anthropogenic climate change starts at year 80 resulting in a positive trend in climate. The values indicated on the panels show the time it takes for the signal to emerge after this year 80 . Climate affects negatively maturation rate (slope of the linear relationship on logit scale: $\beta=-0.125) . Y$-axis is different for each species

(red line) and the associated envelope of natural variability based on a $95 \%$ prediction interval (gray). ToE $\mathrm{E}_{\text {climate }}$ is the time when the projected future conditions under the influence of climate change, "forced conditions" (red lines), exceeds a pre-defined threshold for emergence that is based on the historical unperturbed conditions (gray area, with the horizontal line illustrating the baseline threshold at which climate change is defined to emerge).

The emergence thresholds are typically based on the percentile of the distribution of the historical and forced projections. They define the prediction intervals at which the signal of climate change emerges from the natural climate variability. We present the results for one threshold of wide confidence envelope with a $95 \%$ prediction interval based on emergence thresholds defined by the 2.5 or 97.5 percentile values of the distribution, where impacts are triggered by the extreme historical conditions only. The analysis with a narrow confidence envelope with emergence thresholds defined by the 20 or 80 percentile values of the confidence interval (i.e., $60 \%$ prediction interval) is shown in appendix (Figure S3). In that case, the system is likely highly sensitive to climate as severe impacts are thought to occur for lower percentile of the climate conditions distribution experienced during the historical run. Our results are qualitatively the same between $95 \%$ and $60 \%$ prediction intervals (Figure 3 vs. Figure S3).

In our simulations, we construct a large ensemble of climate time series for both the historical and forced environments for various natural climate variability $\left(\sigma^{2}\right)$ and warming trends $(\alpha)$. Specifically, the historical climate time series are obtained by sampling into a normal distributioncentered on a zero mean and with a specific standard deviation $\sigma$-with independent draws each year (i.e., independent and identically distributed random variables [IID]). The forced climate time series are calculated by adding to this natural variability a linear trend of slope $\alpha$. In that context, this ToE calculation in an IID environment is directly related to the signal-to-noise ratio: $\mathrm{ToE}=(2 \mathrm{P}) /(\mathrm{SN}$ ratio) with $P$ the climate value corresponding the threshold of the prediction interval.

In our theoretical study, we explore a range of parameters consistent with the observed standard deviation of the inter-annual temperature variability (figure 1 of Hawkins \& Sutton, 2012) and the projected climate warming by 2100 (IPCC), with $\sigma_{C} \in[0.21 .5]$ and $\alpha_{C} \in[0.010 .15]$ (Figure 2). In our empirical example, we used 40 members from the Community Earth System Model Large Ensemble (CESM-LE, Kay et al., 2015) to characterize the confidence envelope of sea ice, hence the $\mathrm{ToE}_{\text {climate }}$ and $\mathrm{ToE}_{\mathrm{pop}}$.

\section{3 | CONCEPTUAL MODEL OF THE TIME OF EMERGENCE IN POPULATION}

The time of emergence depends both on (1) the time-varying signal, $T(t)$ estimated as the long-term monotonic trend (red trend in Figure 1) and (2) the noise based on the range of natural variability over some historical period (variations of the black time series in Figure 1, Section 2). Hence, it is important to understand how the climate-driven trend in population growth rate and its year-specific stochastic variations are related to climate trend and variability (Section 3.2, Figure 1). Although previous 
WILEY- Global Change Biology

(a)

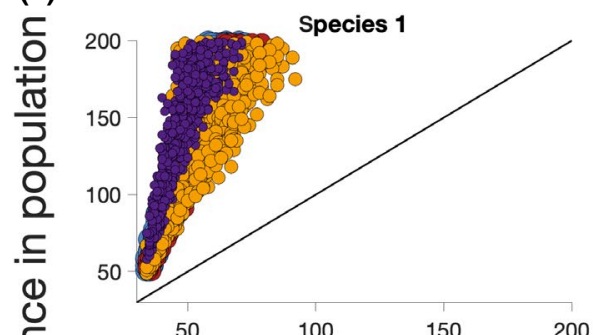

50

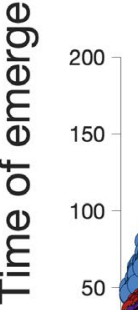

(b)

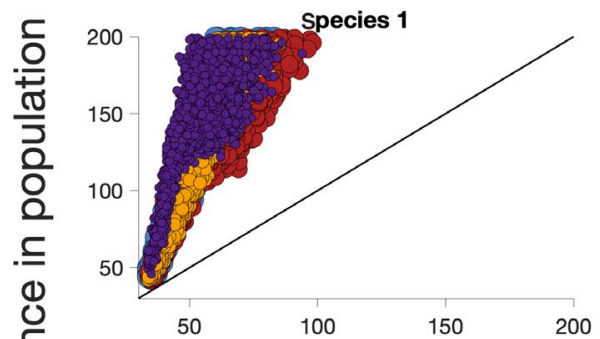

क्ष

일

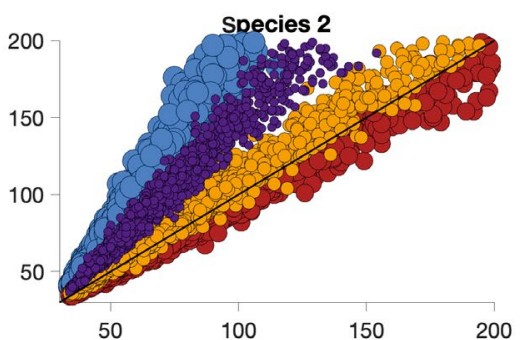

Species 4

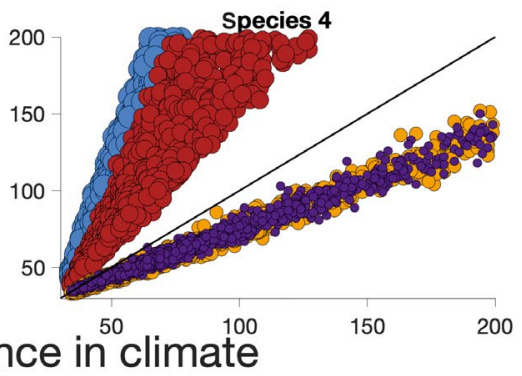

FIGURE 3 Relationship between $\mathrm{ToE}_{\text {climate }}\left(x\right.$-axis) and $\mathrm{ToE}_{\mathrm{pop}}$ ( $y$-axis) for four life-history strategies (from fast (species 1) to slow (species 4)), whereby climate affects only one demographic parameter at a time (colored dots: blue is fertility, red is juvenile survival, orange is adult survival, and purple is maturation rate). Black lines represent the time when $\mathrm{ToE}_{\mathrm{pop}}=\mathrm{ToE}_{\text {climate }}$
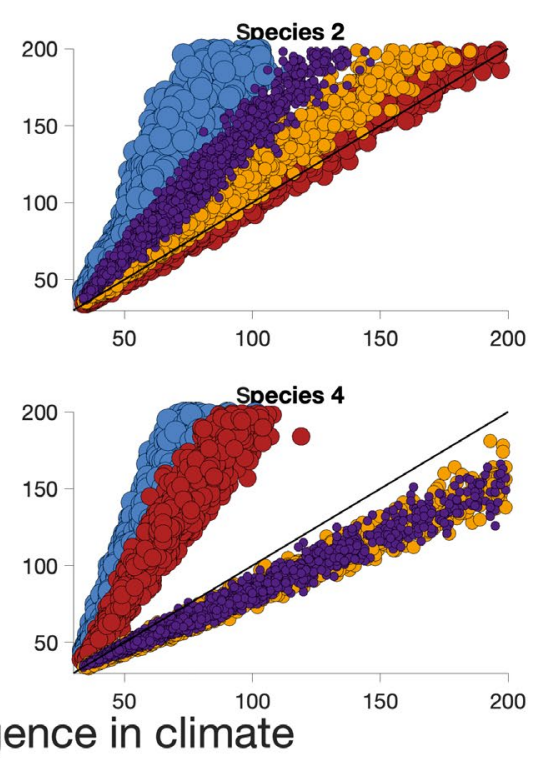

theoretical studies have shown that the variance in annual population growth rates depends on the variance in climate in a stationary environment (Engen et al., 2005), we still lack a theoretical understanding on how the population trend and variability respond to climate in a non-stationary environment. Hence, after introducing the methods to estimate the time of emergence in population (Section 3.1), we discuss conceptually the links between the trend and variability of population and climate (Section 3.2, Figure 1). In addition, to partially shedding light on those concepts, we build on previous theoretical studies (Engen et al., 2005; Morris et al., 2008) to show analytically how the variance in annual population growth rates can be related (linearly for small environmental changes) to the climate variance in a stochastic and stationary environment by explicitly accounting for the functional relationship between climate and demographic rates (Section 3.3, Equation 8).

\section{1 | Methods to estimate $\operatorname{ToE}_{\text {pop }}$}

As in climate (Section 2), population ecologists can use various methods to estimate the time of emergence in population $\mathrm{ToE}_{\mathrm{pop}}$. Figure 2 illustrates the signal threshold method used here (Section 2), where the time of emergence is the first year when the projected future state of a variable crosses a pre-defined emergence threshold based on the historical variations. For example, the projected future state of a population can be depicted by the gray envelope of future projections (red lines in Figures 1 and 2) under a specific forcing scenarios based on a range of emissions of greenhouse gases (GHGs), while the emergence threshold can be determined from the gray envelope of historical population projections (black lines in Figures 1 and 2).

In ecological impact studies, the emergence threshold (e.g., horizontal lines in Figures 1 and 2) can be interpreted as thresholds beyond which management-relevant impacts will occur and depend on 
the management sensitivity to changes in climate conditions. Indeed, emergence thresholds are not necessarily set at the extreme $2.5 \%$ high or $2.5 \%$ low of the range of historical population variations $(\sim 2 \sigma)$ usually used in risk impact studies but can be set at any thresholds at which the decline or increase in population is perceived as unsustainable. For example, high management sensitivity threshold may be desirable for increasing species, whereby management actions are triggered by low emergence thresholds, for example, $60 \%$ prediction interval of population growth distribution during the baseline period (Figure S3).

\subsection{Factors influencing the $\mathrm{ToE}_{\mathrm{pop}}$}

Figure 2 shows that the time of emergence in populations varies among species. From a conceptual viewpoint, this depends on the sensitivity of the population growth rate to climate: $\partial \lambda / \partial C$ (Figure 1) This sensitivity can be decomposed into two main components. First, it depends on the sensitivity of the demographic rates themselves $\theta_{\mathrm{i}}$ (e.g., survival, reproduction) to climate $\partial \theta_{i} / \partial C$ (panel 1 in the demographic rates box in Figure 1). Therefore, the functional relationships between climate and the demographic rates likely play a key role in the sensitivity of the population growth rate to climate. Second, $\partial \lambda / \partial C$ depends on the sensitivity of the population growth rate to demographic rates $\partial \lambda / \partial \theta_{\mathrm{i}}$ (panel 2 in the demographic rates box in Figure 1). The latter is influenced by the species' life history (Saether \& Bakke, 2000). For instance, the "demographic buffering" hypothesis posits that in long-lived species, adult survival is expected to be buffered against environmental changes (environmental canalization sensu Gaillard \& Yoccoz, 2003) and reproduction is expected to be more variable with stronger functional relationships with climate. The opposite patterns are expected in short-lived species (see Hilde et al., 2020 for a review). Therefore, demographic rates of species with contrasting life histories are expected to be differently influenced by climate, influencing, in turn, the sensitivity of the population growth rate to climate, the variance in annual population growth rates, and the climate-driven change in population. As a result, time of emergence in populations is expected to vary among species, but the pattern of such variations is difficult to predict conceptually. Indeed, in next section, we show that the magnitude of the demographic response to climate (i.e., $\partial \theta_{i} / \partial C$ ) increases both the variance and the climate-driven trend of the population, with effect size that varies with the mean state of climate (see Appendix S1 and Figure 1), hence unknown resulting impact on $\mathrm{ToE}_{\mathrm{pop}}$.

\section{3 | Population variability in a stationary environment}

In this section, we show how the variance in annual population growth rates depends on the variance in climate, $\sigma^{2}$, and the functional relationship between the mean climate $\bar{C}$ and demographic rates, assuming a stationary environment (i.e., one in which the mean $\bar{C}$ and variance $\sigma^{2}$ do not vary over time). For a structured population model of the form $\mathbf{n}_{t+1}=\mathbf{A}_{t} \mathbf{n}_{t}$ (see Section 4, Figure 1) in a stationary environment characterized by small variations, the environmental variance of the population growth rate $\lambda_{t}$ (such that $N_{t+1}=\lambda_{t} N_{t}$ ) can be approximated (first-degree Taylor approximation) by (see Engen et al., 1998, 2005):

$$
\operatorname{var}\left(\lambda_{t}\right)=\sum_{i, j} \frac{\partial \lambda}{\partial \theta_{i} \mid \theta_{i}=\overline{\theta_{i}}} \frac{\partial \lambda}{\partial \theta_{j}} \underset{\mid \theta_{j}=\overline{\theta_{j}}}{ } \operatorname{Cov}\left(\theta_{i}, \theta_{j}\right)
$$

with $\bar{\theta}$, the vector of mean demographic parameters including fertility, survival of juveniles and adult, and maturation rates (Table 1).

This variance is important as it influences the long-term stochastic growth rate of the population:

$$
\log \lambda_{s}=\lim _{T \rightarrow \infty} \frac{1}{T} \log \left\|\mathbf{A}_{T-1} \cdots \mathbf{A}_{0} n(0)\right\|
$$

Let us assume that the environment affects only one demographic rate, $\theta_{i}$ (the other rates $\theta_{j}$ remain constant over time), then Equation (1) simplifies as:

$$
\operatorname{var}\left(\lambda_{t}\right)=\left({\frac{\partial \lambda}{\partial \theta_{i \mid \theta_{i}=\bar{\theta}_{i}}}}\right)^{2} \operatorname{var}\left(\theta_{i t}\right)
$$

The demographic rate $\theta_{i}$ is a function of a climatic variable $C_{t}$. $\theta_{i}$ is also affected by other unknown variables generating environmental stochasticity $\varepsilon$, such as observation and process errors. $\varepsilon$ is a stochastic environmental noise of mean 0 , and variance $\operatorname{var}\left(\varepsilon_{t}\right)$ and is considered as an additional variability independent from $C$. For example, let us assume that $\theta_{i}$ is an inverse logit function of a linear function of $C$ :

$$
\theta_{i t}=\theta_{i}\left(C_{t}, \varepsilon_{t}\right)=g\left(y=\beta_{0} C_{t}+\beta_{1}+\varepsilon_{t}\right)
$$

where $\beta_{0}$ and $\beta_{1}$ are the constant regression coefficient of the functional relationship between climate and the demographic rate (Figure $1) ; g$ is the inverse logit link function so that $\theta_{i} \in[01]$. Applying the second-order Taylor expansion, the variance of the demographic rate $\theta_{i}$ is:

$$
\operatorname{var}\left(\theta_{i t}\right) \approx\left(g^{\prime}(\bar{y})\right)^{2} \operatorname{var}(y)=\left(\frac{\partial \theta_{i}}{\partial C}{ }_{\mid C=\bar{C}}\right)^{2}\left(\beta_{0}^{2} \sigma^{2}+\operatorname{var}\left(\varepsilon_{t}\right)^{2}\right),
$$

with $\sigma^{2}$ the variance of the climatic variable $C$ and

$$
\frac{\partial \theta_{i}}{\partial C_{C=\bar{C}}}=y^{\prime} \frac{\exp (-y)}{(1+\exp (-y))^{2}}=\beta_{0} \frac{\exp \left(-\beta_{0} \bar{C}-\beta\right)}{\left(1+\exp \left(-\beta_{0} \bar{C}-\beta_{1}\right)\right)^{2}}
$$

Hence, Equation (3) can be simplified as:

$$
\operatorname{var}\left(\lambda_{t}\right)=\left(\frac{\partial \lambda}{\partial \theta_{i \theta_{i}=\overline{\theta_{i}}}}\right)^{2}\left({\frac{\partial \theta_{i}}{\partial C}}_{\mid \mathcal{C}=\bar{C}}\right)^{2}\left(\beta_{0}^{2} \sigma^{2}+\operatorname{var}\left(\varepsilon_{t}\right)^{2}\right)
$$


Applying the derivative chain rule and assuming $\varepsilon=0$, that is, that the demographic rate $\theta_{i}$ is a deterministic function of climate, like in our simulations, we obtain:

$$
\operatorname{var}\left(\lambda_{t}\right)=\beta_{0}^{2} \sigma^{2}\left(\frac{\partial \lambda}{\partial C}_{\mid C=\bar{C}}\right)^{2}
$$

Hence, the year-specific stochastic variation depends on climate internal variability $\sigma^{2}$, the stochastic environmental variability, as well as the sensitivity of the population growth rate to the demographic rate and the sensitivity of the demographic rate to climate in a stationary environment that both define the overall the sensitivity of the population growth rate to climate.

In a non-stationary environment (Figure 1$), \bar{C}$ is changing, and $\operatorname{var}(\lambda)$ varies, in general, nonlinearly with $\bar{C}$ depending on the sensitivity of the population growth rate to climate $(\partial \lambda / \partial C)$ (see Appendix S2 and Figure 1), this latter also influences the population trend. Hence, it is difficult to posit a priori how $\mathrm{ToE}_{\text {pop }}$ will vary with the signal and noise in climate across life histories and demographic processes for various functional relationship between climate and demographic rates. In Section 4 , we use a simulation framework to answer our five questions posed in the introduction, and discuss six testable hypotheses in Section 6

\begin{tabular}{|c|c|c|c|c|}
\hline & Species 1 & Species 2 & Species 3 & Species 4 \\
\hline \multicolumn{5}{|l|}{ Life history strategies } \\
\hline Reproductive strategy & Semelparous & Iteroparous & Iteroparous & Iteroparous \\
\hline Developmental strategy & Precocious & Precocious & Delayed & Ex-Delayed \\
\hline Survival strategy & Short-lived & Short-lived & Long-lived & Ex-Long-lived \\
\hline \multicolumn{5}{|l|}{ Demographic rates } \\
\hline Annual fertility rate & 5.06 & 3.00 & 1.00 & 0.50 \\
\hline Juvenile survival prob. & 0.20 & 0.30 & 0.40 & 0.60 \\
\hline Adult survival prob. & 0.03 & 0.39 & 0.83 & 0.93 \\
\hline Maturation rate & 0.95 & 0.60 & 0.30 & 0.11 \\
\hline \multicolumn{5}{|l|}{ Life history outcomes } \\
\hline Generation time & 2.04 & 2.77 & 7.40 & 16.30 \\
\hline Life expectancy at birth & 1.21 & 1.47 & 2.39 & 4.17 \\
\hline $\begin{array}{l}\text { Remaining life at } \\
\text { adulthood }\end{array}$ & 1.03 & 1.63 & 6.02 & 14.29 \\
\hline $\begin{array}{l}\text { Probability to return to } \\
\text { adult state }\end{array}$ & 0.03 & 0.39 & 0.83 & 0.93 \\
\hline
\end{tabular}

Note: The fertility ( $F$ is the number of offspring that are produced per adult female in year $t$ ) is reported here. The fecundity ( $b$ is the number of offspring born per unit time per female) is discounted by the probability that an adult will actually survive from the time of the census to the birth pulse $\left(F=b S_{a}\right)$. The deterministic population growth rate is one for all species. The generation time (in years) is the mean age of parents (equation 14 of Bienvenu \& Legendre, 2015), from the fundamental matrix the following demographic outputs are calculated: the mean life expectancy at birth and the mean remaining life at adulthood (equation 20 of Roth \& Caswell, 2018); the probability to return to the adult state (from equation 47 of Roth \& Caswell, 2018 using state A in Figure 2). Ex stands for extreme.

\section{4 | TIME OF EMERGENCE IN POPULATIONS}

\section{1 | Population projections}

To project the population dynamics of species with four contrasting life histories along the slow-fast gradient (Table 2), we use a simple two-stage climate-dependent population matrix model that permits to explore some of the diversity of life cycles (Caswell, 2001; Neubert \& Caswell, 2000; Figure 1). The model distinguishes non-reproducing juveniles and reproducing adults (see life cycle in Figure 1). The population is projected from year $t$ to year $t+1$ by:

$$
\mathbf{n}_{\mathbf{t}+1}=\mathbf{A}\left(\theta\left\lfloor\left(\mathbf{C}_{\mathbf{t}}\right)\right\rfloor\right) \mathbf{n}_{\mathbf{t}},
$$

with $n_{t}$ the population vector made of the abundances of juveniles and adults and $\mathbf{A}$ the population transition matrix including demographic rates $\theta\left[\left(\mathbf{C}_{\mathbf{t}}\right)\right]$ that are defined by specific functional relationship with climate $C$ (Figure 1, Figure S1). The demographic rates are the survival of juveniles $S_{j}$ and adults $S_{a}$, the development rate of juveniles into adults $\gamma$ (maturation rate), and the fertility of adults $F$.

$\mathbf{A}=\left[\begin{array}{ll}S_{j}(1-\gamma) & F \\ S_{j} \gamma & S_{a}\end{array}\right]$.

TABLE 2 Demographic rates and outcomes for the four life-history strategies (species in columns) 
This model permits the simulation of population dynamics of species with four contrasting life histories with increasing generation time (the mean age of mothers at child birth), which is a reliable metric to rank species along the continuum of lifehistory variation (Gaillard et al., 2005). Species differ in terms of reproductive strategy (semelparous vs. iteroparous), age at first reproduction (precocial vs. delayed; Neubert \& Caswell, 2000), and lifespan (short vs. long) and thus range along the slow-fast continuum of life-history variation (Gaillard et al., 2016) from fast species with short generation time, high reproductive output, and short lifespan (species 1 ) to slow species with opposite characteristics (species 4; Table 2). For example, species 1 represents organisms with rapid life cycle development, only one reproductive event in their lifetime and high fecundity $(b \sim 168$ ) (Table 2$)$, such as many annual plants and insects. Species 2 are short-lived iteroparous species producing 7-8 offspring per unit time per female such as small mammals and birds. At the other end of the spectrum, species 4 are long-lived species with delayed first reproduction, low reproductive output per breeding event, and long lifespan such as primates, whales, or albatross. While these species do not capture the full diversity of life history, especially for plants that exhibit a vast amount of life-history variations, they provide a reasonable sample of characteristic traits across a representative range. Indeed, Salguero-Gómez et al. (2016) showed that the first axis of life-history variations of 418 plant species worldwide representing the slow-fast continuum explains $34 \%$ of the variation in plant life-history strategies, while it explains even a higher percentage of variations (60\%-80\%) among mammals (Oli, 2004), birds (Sæther, 1987), and reptiles (Bauwens \& Diaz-Uriarte, 1997).

We include the effects of climate acting on only one demographic parameter at a time $\theta_{i}$ and assume that the inter-annual variability in population growth rates is induced by climate only (i.e., $\varepsilon=0$ in Equation 7). In each case, the functional relationship between demographic rates and climate $\theta_{i}(C)$ is linear, sigmoid, or a bell-shaped curve functions (Figure 1, Figure S1) and is defined by Equation 4 with $\varepsilon=0$ and $\beta_{1}=\overline{\theta_{i h}}$ the mean demographic parameter in the historical unperturbed environment that leads to a stable population with $\bar{C}=0$ (Table 1). Specifically, relationships can be linear functions on the real scale, with

$$
\theta_{i}\left(C_{t}\right)=\beta_{0} C_{t}+\overline{\theta_{i h}}
$$

and results are shown only in Figure S4 for all demographic rates. Relationships can be sigmoid functions, with

$$
\theta_{i}\left(C_{t}\right)==g\left(y=\beta_{0} C_{t}+\overline{\theta_{i h}}\right)
$$

and $g$ is the inverse logit link function. Relationships can be bell-shaped curves functions with quadratic functional relationship between demographic rate and climate:

$$
\theta_{i}\left(C_{t}\right)==g\left(y=\beta_{0} C_{t}^{2}+\overline{\theta_{i h}}\right)
$$

For most demographic rates, $g$ is the inverse logit link function so that $\theta_{i} \in\left[\begin{array}{l}0 \\ 1\end{array}\right]$, but not for fertilities of species 1-3 that vary on the real scale.

To characterize a reasonable range of demographic rates and lifetime outcomes in the set of projected environmental conditions, $\beta_{0}$ varies in a specific range that depends on the functional relationship. For linear functional relationships between climate and demographic parameters (Equation 11), the slope varies as $\beta_{0} \in[-0.030 .03]$ (Figure S4). For sigmoid functional relationships, the slope varies as $\beta_{0} \in[-0.150 .15]$ (Figure 3a). For bell-shaped functional relationships the slope vary as: $\beta_{0} \in[-0.025$ to 0.01$]$ (Figure $3 b$ ).

We calculate the time of emergence of population using the threshold methods following the same methodology as for climate (Section 2). We assume that the historical population is stable in an unperturbed stationary environment with $\bar{C}=0$ and variance $\sigma^{2}$; that is, the stochastic long-run growth rate is null: $\ln \left(\lambda_{s}\right)=0$ (calculated from Equation 2). $\ln \left(\lambda_{\mathrm{s}}\right)$ depends on variance in annual population growth rates $\operatorname{var}(\lambda)$ (Lande et al., 2003; Tuljapurkar \& Orzack, 1980) that is driven by the natural climate variability $\sigma^{2}$ (Section 3 ). Climate fluctuations that increase the variance of demographic rates usually decrease the stochastic long-run growth rate of populations (Engen et al., 2005; Lande et al., 2003; Tuljapurkar, 1982). Hence, to set $\ln \left(\lambda_{s}\right)=0$ across environmental historical conditions, the vector of demographic parameters $\theta$ is slightly tuned for each environmental variability $\sigma$.

\subsection{Time of emergence in population depends on climate variability and trend}

We found that $\mathrm{ToE}_{\text {pop }}$ can be predicted by the climate signal-to-noise ratio and occurs earlier as the signal-to-noise in climate becomes larger (Figure 3). Indeed, the $\mathrm{ToE}_{\mathrm{pop}}$ is linearly and positively correlated to the $\mathrm{ToE}_{\text {climate }}$ (Figure 3 ) as both the variability and trend in population are positively related to the natural variability and trend of climate (Figure 4).

Remarkably, the $\mathrm{ToE}_{\text {pop }}$ can be earlier or later than the $\mathrm{ToE}_{\text {climate, }}$, depending on the life-history strategies and the demographic processes by which climate affects demographic rates (Figure 3). For example, the $\mathrm{ToE}_{\mathrm{pop}}$ is earlier than $\mathrm{ToE}_{\text {climate }}$ for iteroparous species for which climate affects maturation or adult survival rates for longlived species (species 3 and 4) or juvenile survival for short-lived species (species 2). Hence, some life histories may permit an earlier detection of the time at which the signal of anthropogenic climate change emerges from the noise of natural climate variability.

\subsection{Time of emergence in population across life histories and demographic processes}

The $\mathrm{ToE}_{\mathrm{pop}}$ can be predicted by life histories and demographic processes (Figures 3 and 5). Across life histories, the $\mathrm{ToE}_{\mathrm{pop}}$ is the largest for species 1 (semelparous short-lived strategy), which have on average the largest population variations (Table 2, Figure 5). Across demographic processes, the $\mathrm{ToE}_{\mathrm{pop}}$ is the longest for the fertility (Table 2). For iteroparous 

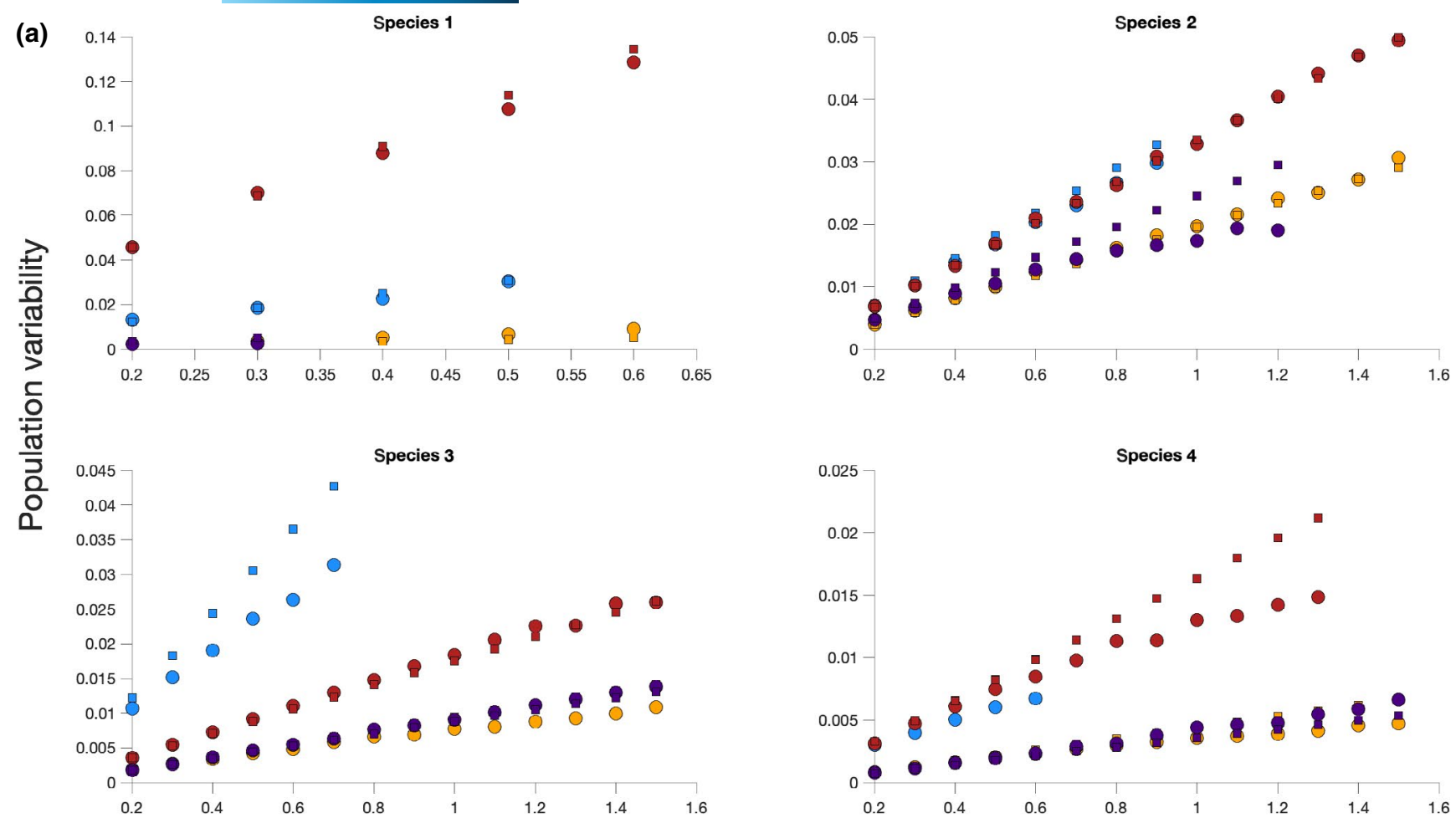

(b)

Climate variability
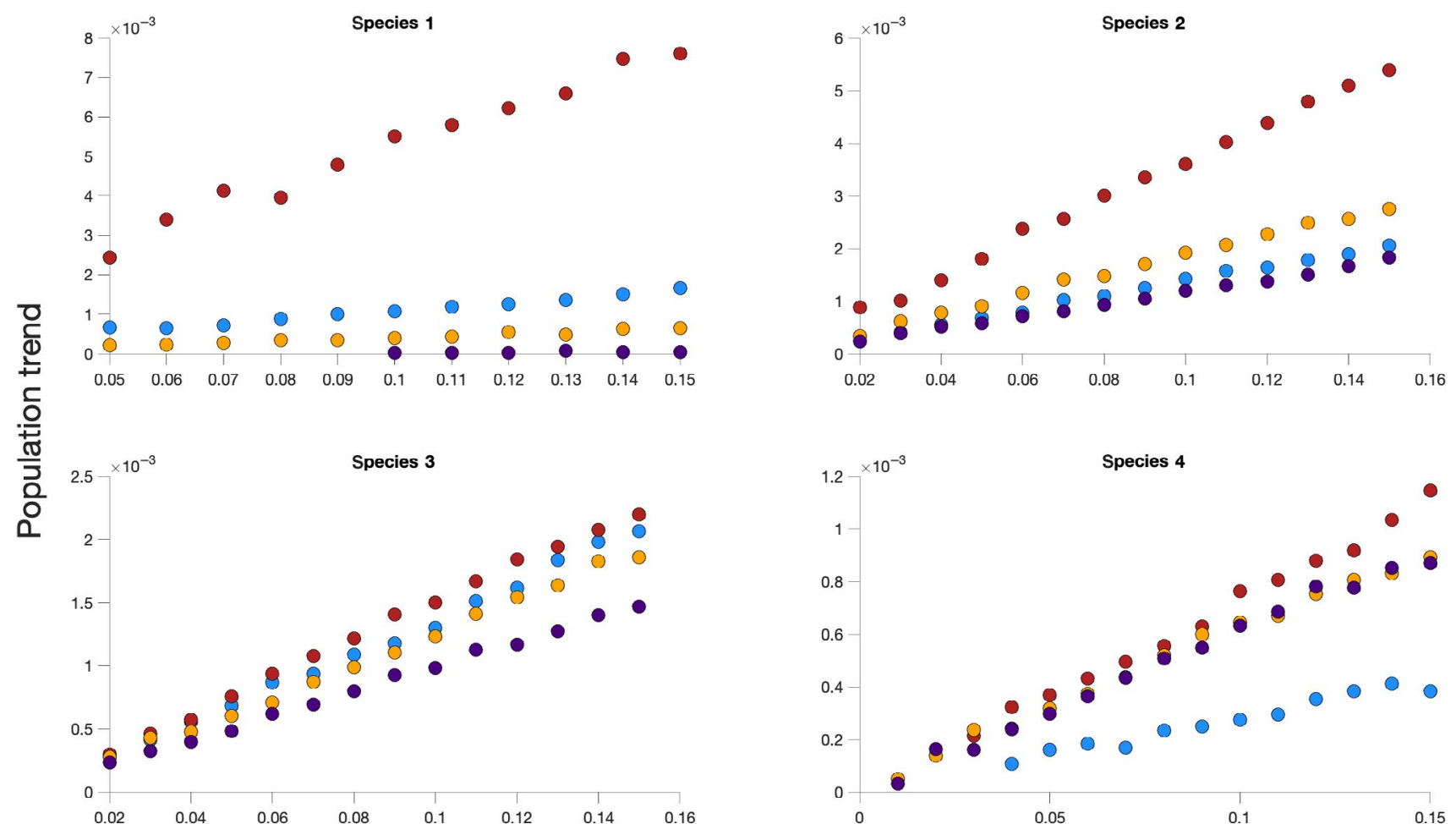

\section{Climate trend}

FIGURE 4 (a) The variability in annual population growth rates depends on the natural variability of climate $\sigma$, in both in the historical and perturbed environments (example for $\beta=0.125, \alpha=0.05$ ). (b) The trend of population growth rate at the time of emergence in population depends on the trend of climate $\alpha$ (example for $\beta=0.125$ and $\sigma=0.5$ ). Colors refer to the climate-dependent demographic rate: blue is fertility, red is juvenile survival, orange is adult survival, and purple is maturation rate. The dots on (a) stand for the forced environment while square shows the historical environment. Panels show four different life-history strategies, from fast (species 1) to slow (species 4) 
species, the $\mathrm{ToE}_{\mathrm{pop}}$ depends on the sensitivity of the population growth rate to the demographic rate affected by climate and occurs earlier as the sensitivity increases (Figure 5). As a consequence, the $\mathrm{ToE}_{\mathrm{pop}}$ occurs later as species longevity increases when climate affects fertility and juvenile survival. However, the opposite pattern occurs when climate affects adult survival and maturation rate: $\mathrm{ToE}_{\mathrm{pop}}$ occurs earlier for longlived than short-lived species (Figure 3, Table 2).

\subsection{Time of emergence in population among different functional relationships between climate and demographic rates}

Surprisingly, the type of functional relationship between climate and demographic rates and its slope have little effect on the $\mathrm{ToE}_{\text {pop }}$ (Figures 3 and 6). While the variability of the population in
FIGURE 5 ToE $_{\text {pop }}$ as function of the sensitivity of the population growth rate to the demographic rate affected by climate. The $\mathrm{ToE}_{\mathrm{pop}}$ is the median trend of climate and various slope in the functional relationship between climate and the demographic rate (Table 2). The sensitivity of the population growth rate the averaged population matrix in the historical environment. Symbols refer to species across various natural variability and to the demographic rate is calculated for
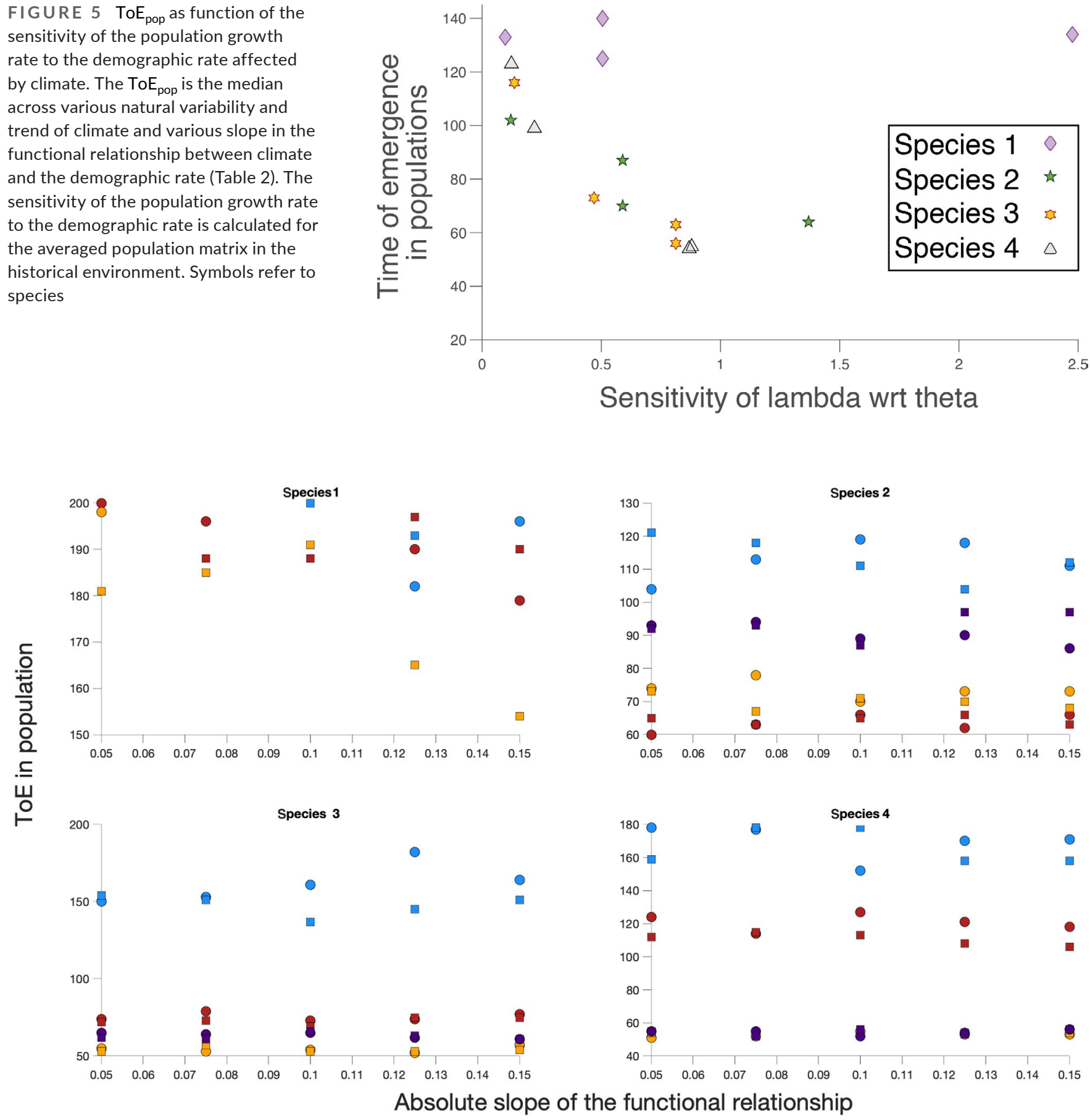

FIGURE $6 \mathrm{ToE}_{\text {pop }}$ as function of the absolute slope of the functional relationship between climate and demographic rate $\beta_{0}$. Example for a climate trend of $\alpha=0.05$ and climate variability of $\sigma=0.5$. Colors refer to demographic pathway by which climate affects demographic rates: blue is fertility, red is juvenile survival, orange is adult survival, and purple is maturation rate. The dots stand for $\beta_{0}>0$, while square shows $\beta_{0}<0$. Panels show four life-history strategies 
TABLE 3 Time of emergence, trend and variability of population growth rate, with its sensitivity to climate across all simulations for four life-history strategies (species in row) and four demographic pathways by which climate affects demography rates (columns)

\begin{tabular}{|c|c|c|c|c|c|c|c|c|}
\hline & \multicolumn{4}{|l|}{ LINEAR } & \multicolumn{4}{|c|}{ BELL SHAPE } \\
\hline & $F$ & $S_{j}$ & $S_{a}$ & $\gamma$ & $F$ & $S_{\mathrm{j}}$ & $\mathrm{S}_{\mathrm{a}}$ & $\gamma$ \\
\hline \multicolumn{9}{|l|}{$\operatorname{ToE}_{\mathrm{pop}}$} \\
\hline Species 1 & 133 & 134 & 125 & 140 & 133 & 126 & 125 & 146 \\
\hline Species 2 & 102 & 64 & 70 & 87 & 106 & 68 & 73 & 86 \\
\hline Species 3 & 116 & 73 & 56 & 63 & 107 & 75 & 60 & 65 \\
\hline Species 4 & 123 & 99 & 54 & 54 & 120 & 105 & 58 & 58 \\
\hline \multicolumn{9}{|c|}{$T_{\text {ToEpop }} / \mathrm{var}_{\text {ToEpop }}$} \\
\hline Species 1 & 0.04 & 0.04 & 0.04 & 0.04 & 0.06 & 0.04 & 0.02 & 0.06 \\
\hline Species 2 & 0.05 & 0.11 & 0.09 & 0.07 & 0.06 & 0.11 & 0.09 & 0.07 \\
\hline Species 3 & 0.03 & 0.08 & 0.15 & 0.11 & 0.01 & 0.08 & 0.14 & 0.12 \\
\hline Species 4 & 0.03 & 0.05 & 0.16 & 0.16 & 0.03 & 0.03 & 0.15 & 0.16 \\
\hline \multicolumn{9}{|l|}{$T_{\text {ToEpop }}$} \\
\hline Species 1 & 0.0010 & 0.0032 & 0.0002 & 0.0003 & 0.0041 & 0.0067 & 0.0001 & 0.0085 \\
\hline Species 2 & 0.0010 & 0.0021 & 0.0010 & 0.0008 & 0.0027 & 0.0021 & 0.0011 & 0.0018 \\
\hline Species 3 & 0.0008 & 0.0008 & 0.0008 & 0.0006 & 0.0007 & 0.0010 & 0.0007 & 0.0005 \\
\hline Species 4 & 0.0002 & 0.0004 & 0.0004 & 0.0003 & 0.0005 & 0.0004 & 0.0003 & 0.0002 \\
\hline \multicolumn{9}{|l|}{$\operatorname{var}_{\text {ToEpop }}$} \\
\hline Species 1 & 0.024 & 0.088 & 0.003 & 0.005 & 0.092 & 0.216 & 0.005 & 0.149 \\
\hline Species 2 & 0.019 & 0.019 & 0.011 & 0.013 & 0.047 & 0.021 & 0.014 & 0.027 \\
\hline Species 3 & 0.024 & 0.010 & 0.005 & 0.005 & 0.054 & 0.013 & 0.005 & 0.005 \\
\hline Species 4 & 0.006 & 0.008 & 0.002 & 0.002 & 0.023 & 0.020 & 0.002 & 0.002 \\
\hline \multicolumn{9}{|l|}{$\frac{\partial \lambda}{\partial C_{C=\bar{C} \text { ToEpop }}}$} \\
\hline Species 1 & 0.010 & 0.019 & 0.003 & 0.004 & 0.0018 & 0.0060 & 0.0002 & 0.0005 \\
\hline Species 2 & 0.012 & 0.024 & 0.011 & 0.009 & 0.0022 & 0.0048 & 0.0023 & 0.0021 \\
\hline Species 3 & 0.014 & 0.009 & 0.010 & 0.007 & 0.0025 & 0.0019 & 0.0021 & 0.0013 \\
\hline Species 4 & 0.001 & 0.003 & 0.005 & 0.004 & 0.0005 & 0.0009 & 0.0011 & 0.0008 \\
\hline \multicolumn{9}{|l|}{$\operatorname{var}\left(\lambda_{t}\right)$} \\
\hline Species 1 & 0.025 & 0.108 & 0.003 & 0.006 & 0.005 & 0.022 & 0.001 & 0.002 \\
\hline Species 2 & 0.019 & 0.019 & 0.011 & 0.014 & 0.003 & 0.004 & 0.002 & 0.003 \\
\hline Species 3 & 0.031 & 0.010 & 0.006 & 0.005 & 0.007 & 0.002 & 0.001 & 0.001 \\
\hline Species 4 & 0.008 & 0.009 & 0.003 & 0.002 & 0.002 & 0.002 & 0.001 & 0.000 \\
\hline
\end{tabular}

Note: Median of the time of emergence of population is denoted ToE $\mathrm{p}_{\mathrm{pop}}$. At the time of emergence in the population: the median of the trend is $T_{\mathrm{ToEpop}}$, the median of the variability in the forced environment is $\operatorname{var}_{\text {ToEpop }}$ and their ratio is $T_{\text {ToEpop }} / \operatorname{var}_{\text {ToEpop }}$ at ToE $E_{\text {pop }}$; and the median of the sensitivity of the population growth rate to climate is $\frac{\partial \lambda}{\partial C_{C=C_{\text {ToEDop }}}}$. Historical variability is denoted $\operatorname{var}\left(\lambda_{t}\right)$.

the historical environment is smaller for bell shape versus linear relationships (see Equation 9, Section 3), both the trend and variability are larger for bell shape relationship in the non-stationary forced environment (Table 3). Indeed, the variability in the forced environment increases substantially compared to the variability in the historical environment for bell shape, while it does not change for linear relationships (Table 3). However, the ratio of the trend to the magnitude of variability is very similar between bell shape and linear relationship, and the patterns of time of emergence are thus very similar regardless of the shape of the functional relationship. The slope of those relationships has also little impact of the $\mathrm{ToE}_{\text {pop }}$ relative to life histories and demographic processes, probably because it affects both the trend and variability simultaneously (Figure 1).

\section{5 | TIME OF EMERGENCE OF EMPEROR PENGUIN POPULATION}

The emperor penguin is a relevant example to test our theoretical predictions, specifically that long-lived species (comparable to species 4) may permit an earlier detection of anthropogenic climate change influence in population growth rates (Figure 3, Section 4.2). Penguins are threatened by future climate change as they rely on sea ice for 
breeding substrate and warming is driving reductions in sea ice cover (Jenouvrier et al., 2014, 2020, 2021). Adult survival is strongly affected by sea ice during four seasons of the life cycle resulting in complex, nonlinear bell shape relationships (Jenouvrier et al., 2012). Adult survival is maximized at intermediate levels of sea ice because neither the complete absence of sea ice (low food resources and/or high predation) nor heavy and persistent sea ice (longer foraging trips) provide satisfactory conditions. Thus, in contrast to our theoretical examples, relationships between climate and demographic rates are even more complex for the emperor penguin. Indeed, sea ice affects a multitude of demographic rates during various seasons, with different functional responses among sexes. Furthermore, other processes contribute to the variability in population growth rate (i.e., $\varepsilon>>0$ in Equation 7, related to sampling variance and process variance due to unmeasured environmental conditions such as local fast ice dynamics or large-scale atmospheric perturbations, see Trathan et al., 2020 for a review).

\subsection{Emperor penguin life cycle}

The life cycle of emperor penguins includes five stages according to breeding status and sex (Figure 7): male and female pre-breeders (birds that have yet to breed for the first time), breeding pairs, and male and female non-breeders (birds that have bred before but do not do so in the current year). The demographic rates describing the transitions between these stages from year $t$ to $t+1$ include the following: the probability that an individual of a given stage returns to the breeding site, the probability of mating as a function of the availability of potential mates, the probability of breeding success (raising an offspring given that the female lays an egg), the primary sex ratio (fixed at 0.5), the survival of offspring during the first year at sea, and the annual survival of pre-breeders, non-breeders, and male and
The functional relationships between demographic parameters and sea ice concentration anomalies depend on four seasons (described in detail in Jenouvrier et al., 2012):

1. The non-breeding season from January to March,

2. The arrival, copulation, and laying period (April-May), hereafter called the laying period,

3. The incubation period (June-July),

4. The rearing period (August-December).

Relationships are sigmoid functions, with linear $\left(\beta_{2}=0\right)$ or quadratic functional relationship between demographic rate and sea ice $\mathbf{x}$ on the logit scale:

$$
\theta_{i}(\mathbf{x}(t))==g\left(y=\beta_{0}+\beta_{1} \mathbf{x}(t)+\beta_{2} \mathbf{x}(t)^{2}+\varepsilon_{t}\right),
$$

including the parameter estimates $\beta_{k}$ and the environmental stochasticity $\varepsilon$ generated by other unknown variables. $\varepsilon$ is a stochastic environmental noise of mean 0 , and variance $\operatorname{var}\left(\varepsilon_{t}\right)$ is considered as an additional variability independent from sea ice. $g$ is the inverse logit link function so that $\theta_{i} \in[0,1]$.

\section{2 | Emissions scenario, climate model, and climate outputs}

The climate outputs from multiple AOGCMs (Atmosphere Ocean General Circulation Model) are publicly available in a standardized format on the Coupled Model Intercomparison Project (CMIP) website. CMIP5 provides a framework for coordinated climate change experiments for assessment in the IPCC Fifth Assessment Report (AR5) in 2014 using four Representative Concentration

\section{Female Male}

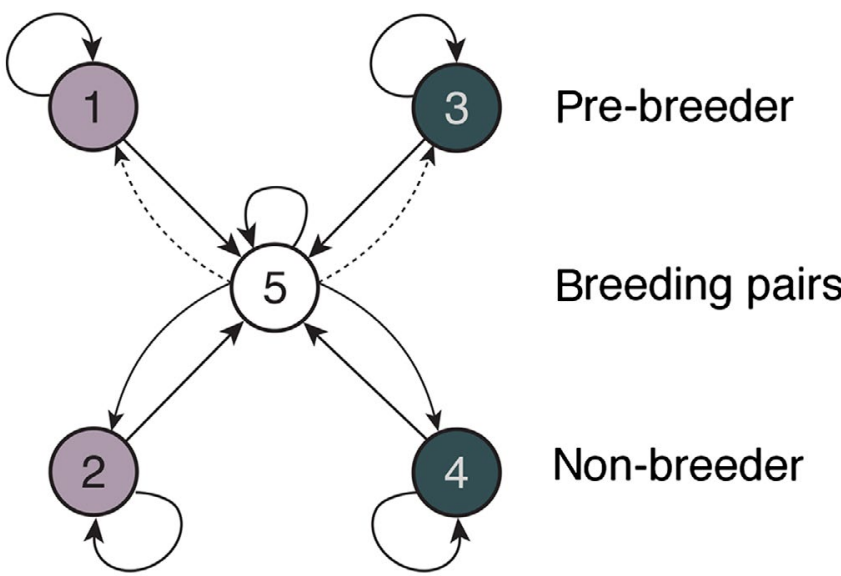

FIGURE 7 Annual life cycle graph for the emperor penguin. It represents a two-sex model with males (black) and females (gray). Fertilities are shown by dotted lines, and the transitions between stages of individuals already present in the population are represented by solid lines (see figure 1 from Jenouvrier et al., 2010 for more details on seasonal cycle of the emperor penguin) 
Pathways (RCP) describing future GHG concentration trajectories based on socio-economic assumptions. Newer emissions forcing scenarios have been developed and used for climate projections in CMIP6 for the Sixth Assessment Report (AR6) released in August 2021. These "Shared Socioeconomic Pathways" (O'Neill et al., 2016) differ in the time evolution of specific climate forcers, such as GHG and aerosol emissions, but bracket the same range in energy flux variations in the atmosphere caused by anthropogenic factors of climate change (i.e., radiative forcing range) as the RCP scenarios.

There are several sources of uncertainties in climate projections that affect the time of emergence, including the structural uncertainty associated with the different climate models used to make projections, and the scenario uncertainty associated with different future emission pathways (Deser et al., 2012; Hawkins \& Sutton, 2009; Schlunegger et al., 2020). However, here we use one climate model and one scenario to obtain the sea ice outputs from a large ensemble (Kay et al., 2015) for illustrative purposes, as large ensemble simulations using several scenarios from several climate models were not available at the time of our analysis.

Specifically, we used RCP 8.5 high-emission scenario (Meinshausen et al., 2011) that represents a future in which greenhouse gas emissions continue unabated. RCP 8.5 is considered as a useful scenario for quantifying physical climate risk, especially over near- to midterm policy-relevant time horizons (Schwalm et al., 2020). Indeed, the total cumulative $\mathrm{CO}_{2}$ emissions since 2005 projected under RCP8.5 by 2020 are in close agreement with historical observed total cumulative $\mathrm{CO}_{2}$ emissions (Schwalm et al., 2020). In addition, the total cumulative $\mathrm{CO}_{2}$ emissions since 2005 projected under RCP8.5 by 2050 agree well with energy forecasts under current and stated policies by 2050 , with still highly plausible levels of $\mathrm{CO}_{2}$ emissions by 2100 (Schwalm et al., 2020).

We use sea ice outputs from a large ensemble produced by the Community Earth System Model (CESM), development of which is coordinated by the National Center for Atmospheric Research (NCAR), allowing us to characterize the natural climate variability (Kay et al., 2015). In addition, the CESM model resolves very well the Antarctic sea ice conditions that influence the most emperor penguin population growth rates (Jenouvrier et al., 2020).

\subsection{Sea ice and penguin projections}

We calculate $\mathrm{ToE}_{\text {pop }}$ for the 54 known colonies around the coast of Antarctica (Fretwell et al., 2012; Fretwell \& Trathan, 2009; Figure S7) following the approach outlined in Section 2 based on projections of population growth rates driven by sea ice changes. Specifically, to project emperor penguin population growth rate at each colony, we link a climate-dependent demographic matrix model to sea ice projections (Section 5.2). Our sea ice-dependent demographic model includes demographic rates that depend on the sea ice conditions during four seasons (non-breeding, laying, incubating, and rearing; Section 5.1), and accounts for differences in the impact of sea ice conditions on adult survival between sexes (see Supporting Information S3 for more details). These relationships and their estimations are described in detail in Jenouvrier et al. (2012). The model includes sources of stochasticity and uncertainties: (1) parameter uncertainty describes statistical uncertainty in the estimates of demographic parameters (e.g., survival, and their responses to sea ice concentration anomalies) and (2) process variance (i.e., environmental stochasticity) reflects true "unexplained" temporal variance in demographic rates that is not accounted for by sea ice, which when combined reflect the term $\operatorname{var}(\varepsilon)$ in Equation (7), Section 3. As we ignored these context-specific uncertainties in our theoretical simulation, we present the results with two scenarios: with or without $\operatorname{var}(\varepsilon)$.

For our historical environment, we used sea ice projections from 1920 to 1950, and for the forced environment we used sea ice projections from 1950 to 2100 under climate scenario RCP 8.5 (Section 5.2). We assume that the population is stable in the historical, unperturbed environment and our emergence threshold is based on the $95 \%$ prediction interval. This permits us to characterize when anthropogenic signals in emperor penguin populations are very likely to emerge from stochastic noise.

\subsection{Time of emergence in sea ice and penguin}

The $\mathrm{ToE}_{\text {climate }}$ in sea ice varies among seasons and colonies (Figure 8, Figure $\mathrm{S} 5$ ) and as a consequence, the $\mathrm{ToE}_{\text {pop }}$ varies among colonies. The ToE in sea ice and populations are earlier for colonies in East Antarctica, than in the Ross, Bellingshausen, Amundsen, and Weddell Seas (Figure S7). The variability and trend are negatively related (Figure $\mathrm{S6}$ ), so regions showing a larger signal also exhibit larger variability in climate and population as sea ice loss are projected into the future. When the environmental stochasticity generated by other factors than sea ice $(\operatorname{var}(\varepsilon))$ is ignored, the $\mathrm{ToE}_{\text {pop }}$ occurs earlier than climate for most colonies, except the ones located from Enderby Land to Terre Adelie Land in East Antarctica for which the ToE in sea ice is the earliest. When parameter uncertainty and process variance are included, the $T_{0} E_{p o p}$ occurs later than $\mathrm{ToE}_{\text {climate }}$ for almost all colonies, except the few colonies in the Bellingshausen and Amundsen Seas for sea ice during the rearing season.

\section{6 | DISCUSSION}

Anthropogenic climate change has triggered impacts on ecosystems worldwide, yet the timing at which these biological impacts can be formally detected has been insufficiently described (Beaumont et al., 2011). Here we focused on detecting climate-driven signals in population, but this approach can be applied to climate-related impacts on changes in distribution by accounting for the temporal dynamics in those spatial changes. Heretofore, changes in distribution are often assumed to depend only on the climate signal and analyses 
using, for example, species distribution models often ignore climate variability (but see Zimmermann et al., 2009).

We found that the time of emergence of climate-driven signals in population dynamics $\mathrm{ToE}_{\text {pop }}$ depends on (1) the magnitude of climate change and variability and (2) life histories and demographic processes by which climate affects the population and we propose six testable predictions. In the context of detection and attribution of climate change, we find that some life histories magnify signal-tonoise ratios in climate ( $\left(\mathrm{TE}_{\text {climate }}\right)$, enabling observations of populations to yield earlier detection of anthropogenic climate change than observations of a climate variable itself, while other demographic dynamics prolong the detection of anthropogenic climate change relative to $\mathrm{ToE}_{\text {climate. }}$

In our emperor penguin example, density-dependent processes occur because of sex-biased mortality in response to sea ice, which displays spatiotemporal autocorrelation, affecting reproduction and survival. These dynamics result in complex covariations among demographic rates, and the life cycle is structured in several stages. Our main theoretical result-some life histories enable an earlier $\mathrm{ToE}_{\text {pop }}$ than $\mathrm{ToE}_{\text {climate }}$-is well supported by our example when the noise is driven by climate natural variability and all complexities arising in natural systems discussed in the following sections are included.

However, when stochastic variations from observation error and other biotic and abiotic processes other than sea ice natural variability are included, the $\mathrm{ToE}_{\mathrm{pop}}$ occurs later than $\mathrm{ToE}_{\text {climate }}$ for almost all colonies. Nevertheless, sampling and process errors can be reduced by increasing monitoring effort and improving our understanding of how the biological systems respond to biotic and abiotic factors. Furthermore, aggregating abundance across space attenuates the random component of the underlying growth rates and may permit a better detection of anthropogenic signals in populations (Che-Castaldo et al., 2017).

Regardless of whether the stochastic noise associated with other sources than natural variability in climate occludes an earlier $\operatorname{ToE}_{\mathrm{pop}}$ than $\mathrm{ToE}_{\text {climate }}$, the time of emergence identifies when the signal of anthropogenic climate change in populations can be quantitatively distinguished from year-specific stochastic variation. Quantifying $\mathrm{ToE}_{\text {pop }}$ is critically needed to provide relevant cost/benefit evaluations for climate mitigation and adaptation strategies, as well as accurate assessments of the risks climate change poses to conservation and management of ecosystems (Hawkins et al., 2020; Hawkins $\&$ Sutton, 2012). In this context, we propose a road map for future research.

\section{1 | $\mathrm{ToE}_{\mathrm{pop}}$ is predicted from $\mathrm{ToE}_{\text {climate }}$}

We find that the $\mathrm{ToE}_{\text {pop }}$ depends almost linearly on the $\mathrm{ToE}_{\text {climate }}$ (Figure 3). Hence, we suggest the following hypotheses.
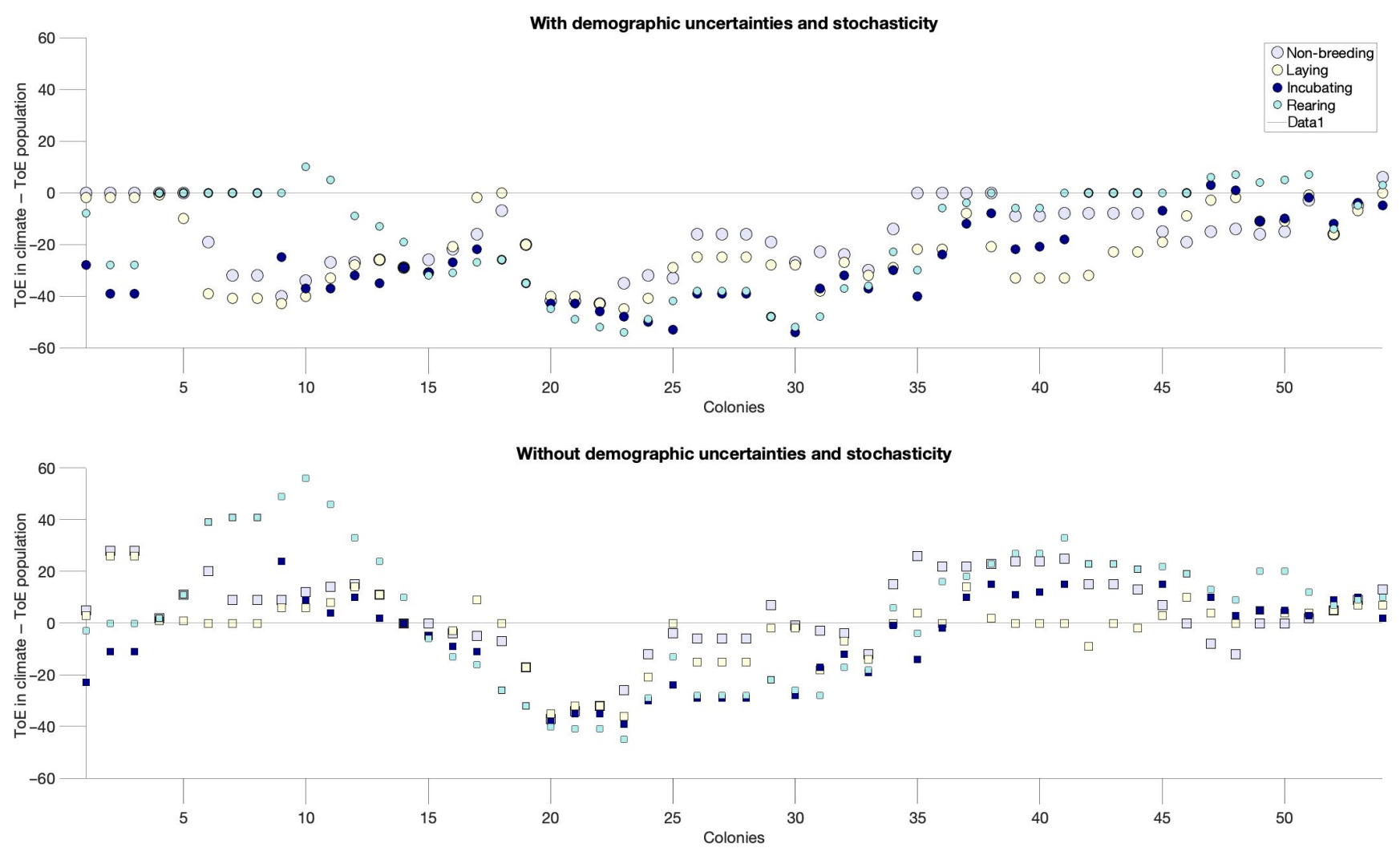

FIGURE 8 Difference between the time of emergence in sea ice and $T_{o} E_{p o p}$ of emperor penguin $\left(T_{o} E_{c l i m a t e}-T_{o} E_{p o p}\right)$ for the 54 known colonies ( $x$-axis) and four seasons (color). The calculation of $\operatorname{ToE}_{\text {pop }}$ accounts for $\operatorname{var}(\varepsilon)$ generated by parameter uncertainty and process variance (i.e., environmental stochasticity) (a) or not (b) 
[H1] Tropical species may permit an earlier detection of anthropogenic climate change than temperate species, especially if temperature in summer affects their demographic rates. Many climate studies have shown that the ToE in temperature is earlier for lowlatitude regions than for mid-latitude regions and is of intermediate duration for polar regions (Hawkins et al., 2020; Hawkins \& Sutton, 2012; Mahlstein et al., 2011, 2012). The emergence of signal of anthropogenic climate warming occurs the soonest in the summer season at low latitudes (Mahlstein et al., 2011). The studies of Beaumont et al. (2011) and Sorte et al. (2019) support this hypothesis: tropical and subtropical ecosystems, and mangroves, face extreme conditions earliest than boreal forests and tundra biomes because the low SD compensates for the relatively small absolute changes (Beaumont et al., 2011). Passerine bird species that migrate between temperate breeding grounds in North America and southern tropical wintering grounds experience an earlier $\mathrm{ToE}_{\text {climate }}$ than species wintering in the subtropics (Sorte et al., 2019). ToE $_{\text {climate }}$ exceeding 2300 occurred only in the northern latitudes corresponding to the southern non-breeding grounds of some birds (Sorte et al., 2019). Studies on the thermal tolerance of terrestrial ectotherms also support this hypothesis. For example, tropical insects are relatively sensitive to temperature change and are currently living very close to their optimal temperature, while species at higher latitudes have broader thermal tolerance and are living in climates that are currently cooler than their physiological optima (Deutsch et al., 2008).

[H2] In terrestrial systems, species affected by temperature may yield earlier detection of anthropogenic climate change than species affected by precipitation. Climate studies have shown that changes in precipitation are often harder to detect because natural variability in precipitation is larger than in temperature (Giorgi \& $\mathrm{Bi}$, 2009). For example, the $\mathrm{ToE}_{\text {climate }}$ in precipitation extremes does not occur prior to 2100 in many regions (King et al., 2015). However, an anthropogenic signal is emerging soon in wintertime heavy precipitation events over much of Eurasia and North America, so species in these regions may experience earlier $\mathrm{ToE}_{\mathrm{pop}}$ . However, this hypothesis depends also on the sensitivity of the population growth rate to temperature versus precipitation. In a comparative study of time series of 165 plants populations around the globe, Compagnoni et al. (2021) found that demographic responses to climate are larger for precipitation than temperature, but large noise hampers the detection of the impact of precipitation on plant populations.

[H3] In marine systems, species dependent on the upper ocean biological cycling of carbon, photosynthetic activity, or salinity may yield later detection of anthropogenic climate change than species affected by sea surface temperature or $\mathrm{pH}$. Several studies found that variables integrating the effect of invading anthropogenic carbon into the global ocean (e.g., $\mathrm{pH}$ ) and sea surface temperature emerged most rapidly while variables related to the upper ocean mixing, associated changes in biological processes (e.g., export of organic matter, primary productivity) and salinity, only emerge after several decades (Henson et al., 2017; Schlunegger et al., 2020).

\section{2 | ToE in population is predicted from life histories and demographic processes}

The $\mathrm{ToE}_{\text {pop }}$ can be also predicted by life histories and demographic processes that will interact with our previous three hypotheses based on the relationships between $\mathrm{ToE}_{\mathrm{pop}}$ and $\mathrm{ToE}_{\text {climate. }}$

$[H 4] T o E_{\text {pop }}$ occurs later in selmeparous species. Semelparous species, such as salmon, bamboos, and monocarpic herbs, exhibit a "big-bang reproduction" whereby individuals die immediately after the first reproduction (e.g., Metcalf et al., 2003). As a consequence, their population dynamics is often more variable than population of iteroparous species. Indeed, the various reproductive events of iteroparous species may be spread out throughout their life as a bet-hedging strategy in unpredictable environments, buffering the effect of environmental variability on population growth rate (Hilde et al., 2020). However, there is little theory available to predict how the degree of iteroparity might influence the demographic response to climate. A comparative study found no correlation between the degree of iteroparity with population responses to climate in plants (Compagnoni et al., 2021). Further work should entail a direct comparison of the influence of the generation time and degree of iteroparity on $\mathrm{ToE}_{\mathrm{pop}}$.

[H5] TheToE $E_{\text {pop }}$ of iteropareous species depends on the sensitivity of the population growth rate to the demographic parameter affected by climate (Figure 5). For population dynamics that are mainly affected by the impact of climate on adult survival during the non-breeding season ("tub" hypothesis; Sæther et al., 2004), the $\mathrm{ToE}_{\text {pop }}$ will occur earlier in long-lived species than short-lived species. This might be the case for many migratory species, when the climate conditions affects survival during the migration, and in the non-breeding quarters (Sorte et al., 2019). The "tap" hypothesis (Sæther et al., 2004) proposes that environmental conditions during the breeding season affect population size the following year because it influences the inflow of new recruits into the population. The $\mathrm{ToE}_{\text {pop }}$ in population occurs earlier if climate conditions during the breeding season have carry-over effect on demographic rates influencing the number of recruits, as observed in many species (e.g., Szostek \& Becker, 2015). Specifically, this will occur when climate affects juvenile survival for short-lived species and maturation rate for long-lived species. Obviously, the underlying processes of the "tub-tap" effects are not mutually exclusive, and multiple demographic rates are affected by climate that will eventually shorten or prolong the $\mathrm{ToE}_{\mathrm{pop}}$.

[H6] Iteropareous species can act as earlier indicators of the detection of anthropogenic climate change than climate itself. Earlier $\mathrm{ToE}_{\text {pop }}$ than $\mathrm{ToE}_{\text {climate }}$ occurs when climate affects the demographic rates that most influence the population growth rate: adult survival and maturity for long-lived iteroparous species and juvenile survival for short-lived ones (Figures 3 and 5). This hypothesis is supported by our empirical example: the population growth rate is mostly sensitive to the adult survival (Jenouvrier et al., 2010), which is affected by sea ice conditions (Jenouvrier et al., 2012). Here, we found that the $\mathrm{ToE}_{\mathrm{pop}}$ occurs earlier than $\mathrm{ToE}_{\text {climate }}$ when process variance due to other environmental factors and 
demographic parameter uncertainties is ignored (Figure 8a). In natural system, the process variance may be large, obscuring an earlier detection of anthropogenic climate change in populations than in climate variables itself (Figure 8b, Sæther et al., 2004, 2007). However, if the goal is to use earlier indicator species in the detection of anthropogenic climate change, it is possible to reduce the demographic parameter uncertainties with higher sampling effort and decrease the process variance by a better understanding of the factors affecting the demographic processes.

\section{3 | Road map for the future}

We provide the first theoretical study of the $\mathrm{ToE}_{\mathrm{pop}}$ to understand the proximate mechanisms of the impact of climate change and variability and demographic processes using a simple model. We illustrate how to use a climate explicit population model to quantify $\operatorname{ToE}_{\text {pop }}$ for emperor penguin, and argue that climate-dependent demographic models could be developed for several species allowing future comparative analysis. But many questions remained unanswered about the effect of more complex climate-driven demographic processes occurring in natural systems such as density dependence, autocorrelation in climate, covariation among demographic rates, population structure, and multiple climate drivers, to name a few. We propose a road map for future research, and acknowledge that we only scratched the surface on these important topics.

\subsection{1 | Comparative studies of the ToE in population using climate explicit population models}

Characterizing the time of emergence requires long-term time series to define the historical unperturbed state. For many species, the unperturbed state benchmark is not available as most long-term ecological time series cover only recent decades while profound global changes were already underway. It is challenging to characterize ToE from observations in natural systems using statistical approaches, even in climate sciences. Hence, most of the climate studies have used climate outputs from atmospheric-oceanic global circulation models (AOGCMs) to quantify the $\mathrm{ToE}_{\text {climate }}$ (Hawkins et al., 2020; Hawkins \& Sutton, 2012). Similarly, we propose to develop climate explicit population models to characterize the ToE in population. We have illustrated our approach using a simple structured population matrix model (Caswell, 2001), but other demographic, trait-based, or eco-evolutionary modeling frameworks can be developed.

We argue that the $\mathrm{ToE}_{\mathrm{pop}}$ can be quantified for many species already (Doak \& Morris, 2010; Sæther et al., 2019; Treurnicht et al., 2016) allowing comparative studies to address our specific hypotheses on the variations of $\mathrm{ToE}_{\mathrm{pop}}$ across regions, ecosystems drivers, and species life histories. In recent decades, there is an increase in the number of studies measuring the effect of climate accounting for multiple seasonal and carry-over effects of climate on the complete life cycle of a species (Cordes et al., 2020; Doak \& Morris, 2010; lles
\& Jenouvrier, 2019; Jenouvrier, 2013; Ozgul et al., 2010). Although fewer studies have developed climate-dependent population model, the information is available in the literature to integrate the statistical relationships between climate and demographic rates into population models. The last step requires an interdisciplinary approach to use climate-dependent population models with projections of historical and future climate from AOGCMs (lles \& Jenouvrier, 2019; Jenouvrier, 2013). AOGCMs project (often nonlinear) changes in climate over time, and critically, provide quantitative estimates of natural climate variability (Kay et al., 2015). We hope that ecologists will take advantage of the free availability of climate outputs in both the pre-industrial, historical, and future environment supervised by the Coupled Model Intercomparison Project (Section 5.2). The most recently completed phase of the project (CMIP6) includes more climate models and output variables than previous phases, and importantly, includes several large ensemble runs of the same AOGCMs and experiment to account for natural variability in climate models (Deser et al., 2020).

Finally, the key to quantifying $\mathrm{ToE}_{\mathrm{pop}}$ is to characterize the population variability in the historical stationary environment. This requires careful consideration of the demographic stochasticity, especially for small populations, environmental stochasticity not driven by climate, density dependence and interactions with other species, which can be incorporated in demographic models (Lande et al., 2003). Other important environmental drivers of population dynamics such as habitat quality and resource variability can be incorporated into demographic models to reduce the process variance in the historical environment, enabling an earlier detection of the impact of climate change on populations. This is particularly important as habitat loss and resources exploitation (land-use change, fisheries, and deforestation) are key threatening processes driving the global loss in biodiversity that have synergistic effects with climate change (Dobson et al., 2021; Lemmer et al., 2021; Mantyka-pringle et al., 2012). If the combined effects of those threats and climate change are greater than the effects of each threat individually, the climate-driven trend in population maybe larger than the climatedriven trend without interaction with other threats, with potentially earlier detection of anthropogenic forced change in populations. On the other hand, if those threats augment noise in the system, that may reduce the signal-to-noise ratio and delay the detection of anthropogenic climate change relative to $\mathrm{ToE}_{\text {climate }}$. For example, the effects of fragmentation and loss of important habitat types will reduce population size and increase the impact of demographic stochasticity on the population dynamics (Hanski \& Gaggiotti, 2004; Lande, 1998), which reduces the power of detecting any signal of climate variation. In addition, environmentally induced fluctuations in population size can be magnified by harvesting (harvest-interaction hypothesis) that may also prolong the $\operatorname{ToE}_{\text {pop }}$ (Gamelon et al., 2019).

\subsection{2 | Density dependence}

Our population model does not include density dependence. The impact on the $\mathrm{ToE}_{\mathrm{pop}}$ will depend on the strength and type of the density 
dependence (negative density dependence: exact compensation, overcompensation, under-compensation, positive density dependence), the specific demographic rate that is affected by density dependence, the interaction between climate and density dependence, and the life history of the species. For example, populations with undercompensating growth tend to respond slowly to environmental changes (Gamelon et al., 2017; Hansen et al., 2019), that may prolong the $\mathrm{ToE}_{\mathrm{pop}}$ . For population declining in response to climate change, the results should be qualitatively similar, except if Allee effects occur (a positive relationship between demographic rates and population), thereby accelerating extinction rate at low density (Courchamp et al., 1999, 2008). The Allee effect will increase the magnitude of the decline of the population trend and $\mathrm{ToE}_{\text {pop }}$ will probably occur earlier (Lande, 1998), but that will depend if an increase variance compensate for this larger signal. For population increasing in response to climate change, the patterns found without density dependence are more likely to change, that will depend on the emergence thresholds and carrying capacity of the population. For example, for invasive species, the emergence thresholds may be defined well below the carrying capacity of the population; hence, the results would be qualitatively the same as without density dependence. However, if the emergence thresholds are defined above the carrying capacity, the signal of anthropogenic climate change in population cannot be formally distinguished from population variability.

\subsection{3 | Temporal autocorrelation in climate and demographic rates}

Our simulated environment does not include autocorrelation in the climate time series, while most environmental variables exhibit a red noise that may increase the probability of extinction of populations (Mustin et al., 2013; Rescan et al., 2020). Environmental variables in reddened environments imply consecutive periods of favorable or unfavorable conditions (positive autocorrelation), and a lower probability of at least one extremely poor year compared with white noise for a given time period, which may both decrease or increase population extinction risk (Schwager et al., 2006). The response of species to colored environmental variations depends on the timescale considered, the strength of environmental fluctuations, the particular life-history traits that are affected by environmental change and the species life cycle defining the sensitivity of population dynamics to these fluctuations (Engen et al., 2013). For example, a study from 454 plant and animal populations found that fast life histories show highest sensitivities to temporal autocorrelation in demographic rates across reproductive strategies, while slow life histories are less sensitive to temporal autocorrelation, but their sensitivities increase for species with a large degree of iteroparity (Paniw et al., 2017). An important question is then how the sensitivities to temporal autocorrelation in demographic rates are related to the $\mathrm{ToE}_{\mathrm{pop}}$, and can be addressed by incorporating such autocorrelation in our current framework. Since the patterns of the sensitivities of the population growth rate to both inter-annual variability and temporal autocorrelation in demographic rates are similar
(Iles et al., 2019; Paniw et al., 2017), and the influence of autocorrelations on the population variability driven by environmental noise is small (Engen et al., 2013), we do not expect that including temporal autocorrelation will change our six hypothesis.

\subsubsection{Correlation among demographic rates}

Correlations among demographic rates can occur when climate affects rates simultaneously and were ignored in our simulations. Positive covariation and autocorrelation in demographic rates tend to increase the variability in demographic rates, decreasing the stochastic growth rate and increasing the variability in population growth rates (Engen et al., 2013; Tuljapurkar et al., 2009). On the opposite, negative covariation and autocorrelation tend to decrease the variability in demographic rates, such as the survival-fecunditytrade-offs that reduces the variance in the population growth rate (Colchero et al., 2019; Sæther \& Engen, 2015). Correlations of opposite signs among the various demographic rates may cancel out the effect of each other, and the resulting effect on the population growth rate may be small. In addition, the life-history strategy and density dependence affect the population responses to covariation and autocorrelation in demographic rates (Colchero et al., 2019; Iles et al., 2019) making challenging to predict how the trend and variability in population, hence the $\mathrm{ToE}_{\mathrm{pop}}$, will be affected by covariation among demographic rates. Demographic rate correlations had the largest effect on the population growth rate for life histories with short to medium generation time (Iles et al., 2019) that may amplify or dampen the detection of anthropogenic climate change.

\subsection{5 | Population structure}

Our population model includes the simplest age-structure by aggregating age-classes into two stages: juvenile and adult. Although this simple life cycle is useful to explore a wide range of life histories (Table 1), it leads to a reduced variance in annual population growth rates in an unperturbed environment (Colchero et al., 2019). In our definition, the $\mathrm{ToE}_{\mathrm{pop}}$ is based on the comparison of the variability between the unperturbed and perturbed environment. Hence, the resulting $\mathrm{ToE}_{\text {pop }}$ should not be highly sensible to the structure of the population, except if the life cycle structure buffers or amplifies the population variability response to population structure in a nonstationary environment.

The life cycle of many species is much more complex than our simulated life histories. For example, the life cycles of plants include cryptic life stages such as long-term seedbanks and dormant adults. The reproduction of plants is highly variable with some plants reproducing vegetatively and seed mass and per-capita seed production ranging typically across six orders of magnitude (Kattge et al., 2011). Plants exhibit also an incredible range of longevity, from weeks to millennia (Peñuelas \& Munné-Bosch, 2010). For example, an alpine carex, Carex curvula is a very slow-growing rhizomatous sedge and 
can have a life span of 2000 years (Steinger et al., 1996). The range of temperature variations that this alpine flora can sustain (i.e., breath of thermal niche) is exceeding the worst climate warming scenarios (Körner \& Hiltbrunner, 2021), suggesting that the time of emergence would be prolonged for those species. Those complex life-history traits are not exclusive to the plant kingdom, and further work focusing on how age, stage, and trait structure affect the dynamics of populations and potentially dampen or amplify the climate-driven variability in population (e.g., cohort resonance, Bjørnstad et al., 2004), will provide fundamental insights to theoretical and applied research of the detection of anthropogenic climate change. For example, Bjørnstad et al. (2004) showed that spectral frequencies of the catches of cod in the Skagerrak were not the dominant frequencies of key environmental drivers, rather there was a spectral shift with a frequency peak at cod generational timescales, the so-called cohort resonance. Population dynamics may also potentially retain a memory of prior forcing, especially when climate events occurring in one season or stage of the life cycle affect individual performance in a subsequent season or stage (e.g., carry-over effects of climate; effect of climate at young age classes that may delay age at first recruitment; Hollowed \& Sundby, 2014; Lindström \& Kokko, 2002; Ranta et al., 2005; effect of climate on dormant stages; Hairston Jr., 1996).

\subsection{6 | Multiple climate drivers}

Our modeling framework includes only a single environmental time series. The cumulative integrations of white-noise atmospheric forcing in ecosystem drivers can generate population responses that are characterized by strong transitions and prolonged apparent state changes in marine ecosystems that will affect the $\mathrm{ToE}_{\mathrm{pop}}$ (Di Lorenzo \& Ohman, 2013). In addition, integrating multiple drivers to characterize the $\mathrm{ToE}_{\text {pop }}$ is important, as different climate variables affect organisms at various seasons and stages of their life cycle, sometimes in opposite ways (Jenouvrier, 2013; Jenouvrier et al., 2018). In a butterfly species, warmer temperatures have a positive effect on the survival of eggs, pre-diapause larvae and pupae but a negative effect on the survival of overwintering larvae (Radchuk et al., 2013). Climatic conditions experienced at different stages cause complex patterns of environmental covariance among demographic rates even across generations, which may either buffer or amplify the signal of anthropogenic climate change, emphasizing the importance of considering the complete life history of individuals when predicting and detecting the effect of climatic change on population dynamics (Herfindal et al., 2015; lles et al., 2019; Jenouvrier, 2013).

\section{7 | CONCLUSION}

In the current global biodiversity crisis, the development of tools to detect, quantify, and compare the signal of anthropogenic climate change is essential to understand, anticipate, and adapt to climate change. Here, we provide a new perspective on how climate-induced changes in populations can be detected by quantifying the time of emergence in populations. We hope that ecologists will embrace the relevance of this concept in their attempt to understand population responses to climate change in non-stationary environments and provide a robust assessment of future climate risk to inform management and policy decisions.

\section{ACKNOWLEDGMENTS}

We thank all the field workers who participated in the emperor penguin long-term study since 1964, and the Institute Paul Emile Victor (Programme IPEV 109), and Terres Australes et Antarctiques Françaises for logistical and financial support in Terre Adélie. We thank Joannie Van de Walle and Remi Fay for their comments on earlier versions of the manuscript and Arpat Ozgul, David Iles, Jimmy Garnier, Mike Neubert, Heather Lynch, and the working group on "Individual heterogeneity in animal ${ }^{\mathrm{TM}}$ 's life histories" for constructive discussions. We acknowledge the support of NASA 80NSSC20K1289 to SJ, ML, and MH; NSF OPP 1744794 to SJ and NSF OPP 2037561 to SJ and MH.

\section{CONFLICT OF INTEREST}

The authors have no relevant financial or non-financial interests to disclose.

\section{AUTHOR CONTRIBUTIONS}

Stéphanie Jenouvrier and Matthew C. Long developed the research ideas, and conceptualized and designed the study. Stéphanie Jenouvrier performed modeling work and analyzed theoretical and empirical data. Christophe F. D. Coste derived the mathematical equations. Marika Holland computed the sea ice forecasts. Stéphanie Jenouvrier wrote the first draft of the manuscript, and all authors contributed substantially to revisions.

\section{DATA AVAILABILITY STATEMENT}

Data are archived on the USAP-DC repository (dataset ID is 601491 and DOI is https://doi.org/10.15784/601491). Data are also archived on HAL, a public repository (hal-03468070).

\section{ORCID}

Stéphanie Jenouvrier (D) https://orcid.org/0000-0003-3324-2383

Christophe F. D. Coste (D) https://orcid.org/0000-0003-3680-5049

Marika Holland (D) https://orcid.org/0000-0001-5621-8939

Marlène Gamelon (D) https://orcid.org/0000-0002-9433-2369

Nigel G. Yoccoz (D) https://orcid.org/0000-0003-2192-1039

Bernt-Erik Sæther (D) https://orcid.org/0000-0002-0049-9767

\section{REFERENCES}

Barnes, E., Anderson, C., \& Ebert-Uphoff, I. (2018). An Al approach to determining the time of emergence of climate change. In Proceedings of the 8th International Workshop on Climate Informatics: Cl 2018 (pp. 19-22). National Center for Atmospheric Research. 
Barnhart, K. R., Miller, C. R., Overeem, I., \& Kay, J. E. (2016). Mapping the future expansion of arctic open water. Nature Climate Change, 6, 280-285.

Barraquand, F., \& Yoccoz, N. G. (2013). When can environmental variability benefit population growth? Counterintuitive effects of nonlinearities in vital rates. Theoretical Population Biology, 89, 1-11. https://doi.org/10.1016/j.tpb.2013.07.002

Bauwens, D., \& Diaz-Uriarte, R. (1997). Covariation of life-history traits in lacertid lizards: A comparative study. The American Naturalist, 149, 91-111. https://doi.org/10.1086/285980

Beaumont, L. J., Pitman, A., Perkins, S., Zimmermann, N. E., Yoccoz, N. G., \& Thuiller, W. (2011). Impacts of climate change on the world's most exceptional ecoregions. Proceedings of the National Academy of Sciences of the United States of America, 108, 2306-2311. https:// doi.org/10.1073/pnas.1007217108

Bienvenu, F., \& Legendre, S. (2015). A new approach to the generation time in matrix population models. The American Naturalist, 185, 834-843. https://doi.org/10.1086/681104

Bjørnstad, O. N., Nisbet, R. M., \& Fromentin, J.-M. (2004). Trends and cohort resonant effects in age-structured populations. Journal of Animal Ecology, 73, 1157-1167. https://doi. org/10.1111/j.0021-8790.2004.00888.x

Boyce, M., Haridas, C., Lee, C., \& Thenceasstochasticdemographyw (2006). Demography in an increasingly variable world. Trends in Ecology \& Evolution, 21, 141-148. https://doi.org/10.1016/j. tree.2005.11.018

Callendar, G. S. (1938). The artificial production of carbon dioxide and its influence on temperature. Quarterly Journal of the Royal Meteorological Society, 64, 223-240. https://doi.org/10.1002/ qj.49706427503

Caswell, H. (2001). Matrix population models (Vol. 2). Sinauer.

Che-Castaldo, C., Jenouvrier, S., Youngflesh, C., Shoemaker, K. T., Humphries, G., McDowall, P., Landrum, L., Holland, M. M., Li, Y., Ji, R., \& Lynch, H. J. (2017). Pan-Antarctic analysis aggregating spatial estimates of adélie penguin abundance reveals robust dynamics despite stochastic noise. Nature Communications, 8, 832. https:// doi.org/10.1038/s41467-017-00890-0

Colchero, F., Jones, O. R., Conde, D. A., Hodgson, D., Zajitschek, F., Schmidt, B. R., Malo, A. F., Alberts, S. C., Becker, P. H., Bouwhuis, S., Bronikowski, A. M., Vleeschouwer, K. M., Delahay, R. J., Dummermuth, S., Fernández-Duque, E., Frisenvænge, J., Hesselsøe, M., Larson, S., Lemaître, J.-F., ... Gaillard, J.-M. (2019). The diversity of population responses to environmenta change. Ecology Letters, 22(2), 342-353. https://doi.org/10.1111/ ele.13195

Compagnoni, A., Levin, S., Childs, D. Z., Harpole, S., Paniw, M., Römer, G., Burns, J. H., Che-Castaldo, J., Rüger, N., Kunstler, G., Bennett, J. M., Archer, C. R., Jones, O. R., Salguero-Gómez, R., \& Knight, T. M. (2021). Herbaceous perennial plants with short generation time have stronger responses to climate anomalies than those with longer generation time. Nature Communications, 12. https://doi org/10.1038/s41467-021-21977-9

Cordes, L. S., Blumstein, D. T., Armitage, K. B., CaraDonna, P. J., Childs, D. Z., Gerber, B. D., Martin, J. G. A., Oli, M. K., \& Ozgul, A. (2020). Contrasting effects of climate change on seasonal survival of a hibernating mammal. Proceedings of the National Academy of Sciences of the United States of America, 117, 18119-18126. https://doi. org/10.1073/pnas.1918584117

Courchamp, F., Berec, L., \& Gascoigne, J. (2008). Allee effects in ecology and conservation. Oxford University Press.

Courchamp, F., Clutton-Brock, T., \& Grenfell, B. (1999). Inverse density dependence and the allee effect. Trends in Ecology \& Evolution, 14 405-410. https://doi.org/10.1016/S0169-5347(99)01683-3

Deser, C., Knutti, R., Solomon, S., \& Phillips, A. S. (2012). Communication of the role of natural variability in future north American climate. Nature Climate Change, 2, 775-779.
Deser, C., Lehner, F., Rodgers, K. B., Ault, T., Delworth, T. L., DiNezio, P. N., Fiore, A., Frankignoul, C., Fyfe, J. C., Horton, D. E., Kay, J. E., Knutti, R., Lovenduski, N. S., Marotzke, J., McKinnon, K. A., Minobe, S., Randerson, J., Screen, J. A., Simpson, I. R., \& Ting, M. (2020). Insights from earth system model initial-condition large ensembles and future prospects. Nature Climate Change, 10, 277-286. https:// doi.org/10.1038/s41558-020-0731-2

Deutsch, C. A., Tewksbury, J. J., Huey, R. B., Sheldon, K. S., Ghalambor, C. K., Haak, D. C., \& Martin, P. R. (2008). Impacts of climate warming on terrestrial ectotherms across latitude. Proceedings of the National Academy of Sciences of the United States of America, 105, 66686672. https://doi.org/10.1073/pnas.0709472105

Di Lorenzo, E., \& Ohman, M. D. (2013). A double-integration hypothesis to explain ocean ecosystem response to climate forcing. Proceedings of the National Academy of Sciences of the United States of America, 110, 2496-2499. https://doi.org/10.1073/pnas.12180 22110

Doak, D. F., \& Morris, W. F. (2010). Demographic compensation and tipping points in climate-induced range shifts. Nature, 467, 959-962.

Dobson, A., Rowe, Z., Berger, J., Wholey, P., \& Caro, T. (2021). Biodiversity loss due to more than climate change. Science, 374, 699-700. https://doi.org/10.1126/science.abm6216

Engen, S., Bakke, Ø., \& Islam, A. (1998). Demographic and environmental stochasticity-concepts and definitions. Biometrics, 54(3), 840 https://doi.org/10.2307/2533838

Engen, S., Lande, R., \& Sæther, B. E. (2013). A quantitative genetic model of $\mathrm{r}$ - and $\mathrm{k}$-selection in a fluctuating population. The American Naturalist, 181, 725-736.

Engen, S., Lande, R., Sæther, B. E., \& Weimerskirch, H. (2005). Extinction in relation to demographic and environmental stochasticity in age-structured models. Mathematical Biosciences, 195, 210-227. https://doi.org/10.1016/j.mbs.2005.02.003

Fretwell, P. T., LaRue, M. A., Morin, P. Kooyman, G. L., Wienecke, B., Ratcliffe, N., Fox, A. J., Fleming, A. H., Porter, C., \& Trathan, P. N. (2012). An emperor penguin population estimate: The first global, synoptic survey of a species from space. PLoS One, 7, e33751.

Fretwell, P. T., \& Trathan, P. N. (2009). Penguins from space: Faecal stains reveal the location of emperor penguin colonies. Global Ecology and Biogeography, 18, 543-552. https://doi. org/10.1111/j.1466-8238.2009.00467.x

Gaillard, J. M., Lemaître, J. F., Berger, V., Bonenfant, C., Devillard, S., Douhard, M., Gamelon, M., Plard, F., \& Lebreton, J. D. (2016). Life histories, axes of variation. Encyclopedia of evolutionary biology (pp. 312-323). Academic Press.

Gaillard, J. M., Mark Hewison, A., Klein, F., Plard, F., Douhard, M., Davison, R., \& Bonenfant, C. (2013). How does climate change influence demographic processes of widespread species? Lessons from the comparative analysis of contrasted populations of roe deer. Ecology Letters, 16, 48-57. https://doi.org/10.1111/ele.12059

Gaillard, J., \& Yoccoz, N. (2003). Temporal variation in survival of mammals: A case of environmental canalization? Ecology, 84, 32943306. https://doi.org/10.1890/02-0409

Gaillard, J.-M., Yoccoz, N G, Lebreton, J.-D., Bonenfant, C., Devillard, S., Loison, A., Pontier, D., \& Allaine, D. (2005). Generation time: A reliable metric to measure life-history variation among mammalian populations. The American Naturalist, 166, 119-123. https://doi. org/10.1086/430330

Gamelon, M., Grøtan, V., Nilsson, A. L. K., Engen, S., Hurrell, J. W., Jerstad, K., Phillips, A. S., Røstad, O. W., Slagsvold, T., Walseng, B., Stenseth, N. C., \& Sæther, B.-E. (2017). Interactions between demography and environmental effects are important determinants of population dynamics. Science Advances, 3, e1602298. https:// doi.org/10.1126/sciadv.1602298

Gamelon, M., Sandercock, B. K., \& Sæther, B. E. (2019). Does harvesting amplify environmentally induced population fluctuations over 
time in marine and terrestrial species? Journal of Applied Ecology, 56 2186-2194. https://doi.org/10.1111/1365-2664.13466

Ghil, M. (2002). Natural climate variability. Encyclopedia of Global Environmental Change, 1, 544-549.

Giorgi, F., \& Bi, X. (2009). Time of emergence (TOE) of GHG-forced precipitation change hot-spots. Geophysical Research Letters, 36. https://doi.org/10.1029/2009gl037593

Hairston, Jr., N. G. (1996). Zooplankton egg banks as biotic reservoirs in changing environments. Limnology and Oceanography, 41, 10871092. https://doi.org/10.4319/lo.1996.41.5.1087

Hansen, B. B., Gamelon, M., Albon, S. D., Lee, A. M., Stien, A., Irvine, R. J., Sæther, B.-E., Loe, L. E., Ropstad, E., Veiberg, V., \& Grøtan, V. (2019). More frequent extreme climate events stabilize reindeer population dynamics. Nature Communications, 10, 1-8. https://doi. org/10.1038/s41467-019-09332-5

Hanski, I. A., \& Gaggiotti, O. E. (2004). Ecology, genetics and evolution of metapopulations. Academic Press.

Hasselmann, K. (1976). Stochastic climate models part I. theory. Tellus, 28, 473-485.

Hawkins, E., Frame, D., Harrington, L., Joshi, M., King, A., Rojas, M., \& Sutton, R. (2020). Observed emergence of the climate change signal: From the familiar to the unknown. Geophysical Research Letters, 47. https://doi.org/10.1029/2019gl086259

Hawkins, E., \& Sutton, R. (2009). The potential to narrow uncertainty in regional climate predictions. Bulletin of the American Meteorological Society, 90, 1095-1108. https://doi.org/10.1175/2009BAMS26 07.1

Hawkins, E., \& Sutton, R. (2012). Time of emergence of climate signals. Geophysical Research Letters, 39, n/a-n/a. https://doi. org/10.1029/2011gl050087

Henson, S. A., Beaulieu, C., Ilyina, T., John, J. G., Long, M., Séférian, R., Tjiputra, J., \& Sarmiento, J. L. (2017). Rapid emergence of climate change in environmental drivers of marine ecosystems. Nature Communications, 8. https://doi.org/10.1038/ncomms14682

Herfindal, I., van de Pol, M., Nielsen, J. T., Sæther, B. E., \& Møller, A. P. (2015). Climatic conditions cause complex patterns of covariation between demographic traits in a long-lived raptor. Journal of Animal Ecology, 84, 702-711. https://doi.org/10.1111/1365-2656.12318

Hilde, C. H., Gamelon, M., Sæther, B. E., Gaillard, J. M., Yoccoz, N. G., \& Pélabon, C. (2020). The demographic buffering hypothesis: Evidence and challenges. Trends in Ecology \& Evolution, 35, 523-538. https://doi.org/10.1016/j.tree.2020.02.004

Hollowed, A. B., \& Sundby, S. (2014). Change is coming to the northern oceans. Science, 344, 1084-1085.

lles, D., \& Jenouvrier, S. (2019). Projected population consequences of climate change. In P. O. Dunn \& A. P. Møller (Eds.), Effects of climate change on birds (2nd ed.). Oxford University Press. https://doi. org/10.1093/oso/9780198824268.003.0012

Iles, D. T., Rockwell, R. F., \& Koons, D. N. (2019). Shifting vital rate correlations alter predicted population responses to increasingly variable environments. The American Naturalist, 193, E57-E64. https:// doi.org/10.1086/701043

IPCC. (2018). Summary for policymakers. In V. Masson-Delmotte, P. Zhai, H.-O. Pörtner, D. Roberts, J. Skea, P. R. Shukla, A. Pirani, W. Moufouma-Okia, C. Péan, R. Pidcock, S. Connors, J. B. R. Matthews, Y. Chen, X. Zhou, M. I. Gomis, E. Lonnoy, T. Maycock, M. Tignor, \& T. Waterfield (Eds.), Global warming of $1.5^{\circ} \mathrm{C}$. An IPCC Special Report on the impacts of global warming of $1.5^{\circ} \mathrm{C}$ above pre-industrial levels and related global greenhouse gas emission pathways, in the context of strengthening the global response to the threat of climate change, sustainable development, and efforts to eradicate poverty. IPCC. In Press

Jenouvrier, S. (2013). Impacts of climate change on avian populations. Global Change Biology, 19, 2036-2057. https://doi.org/10.1111/ gcb.12195
Jenouvrier, S., Barbraud, C., \& Weimerskirch, H. (2005). Long-term contrasted responses to climate of two Antarctic seabirds species. Ecology, 86, 2889-2903.

Jenouvrier, S., Caswell, H., Barbraud, C., \& Weimerskirch, H. (2010). Mating behavior, population growth, and the operational sex ratio: A periodic two-sex model approach. The American Naturalist, 175, 739-752. https://doi.org/10.1086/652436

Jenouvrier, S., Che-Castaldo, J., Wolf, S., Holland, M., Labrousse, S., LaRue, M., Wienecke, B., Fretwell, P., Barbraud, C., Greenwald, N., Stroeve, J., \& Trathan, P. N. (2021). The call of the emperor penguin: Legal responses to species threatened by climate change. Global Change Biology, 27(20), 5008-5029. https://doi.org/10.1111/ gcb.15806

Jenouvrier, S., Desprez, M., Fay, R., Barbraud, C., Weimerskirch, H., Delord, K., \& Caswell, H. (2018). Climate change and functional traits affect population dynamics of a long-lived seabird. Journal of Animal Ecology, 87, 906-920. https://doi.org/10.1111/1365-2656.12827

Jenouvrier, S., Holland, M., Iles, D., Labrousse, S., Landrum, L., Garnier, J., Caswell, H., Weimerskirch, H., LaRue, M., Ji, R., \& Barbraud, C. (2020). The Paris agreement objectives will likely halt future declines of emperor penguins. Global Change Biology, 26, 1170-1184. https://doi.org/10.1111/gcb.14864

Jenouvrier, S., Holland, M., Stroeve, J., Barbraud, C., Weimerskirch, H., Serreze, M., \& Caswell, H. (2012). Effects of climate change on an emperor penguin population: Analysis of coupled demographic and climate models. Global Change Biology, 18, 2756-2770. https://doi. org/10.1111/j.1365-2486.2012.02744.x

Jenouvrier, S., Holland, M., Stroeve, J., Serreze, M., Barbraud, C., Weimerskirch, H., \& Caswell, H. (2014). Projected continent-wide declines of the emperor penguin under climate change. Nature Climate Change, 4, 715-718. https://doi.org/10.1038/nclimate2280

Kattge, J., Díaz, S., Lavorel, S., Prentice, I. C., Leadley, P., Bönisch, G., Garnier, E., Westoby, M., Reich, P. B., Wright, I. J., Cornelissen, J. H. C., Violle, C., Harrison, S. P., Van Bodegom, P. M., Reichstein, M., Enquist, B. J., Soudzilovskaia, N. A., Ackerly, D. D., Anand, M., ... Wirth, C. (2011). Try-A global database of plant traits. Global Change Biology, 17, 2905-2935. https://doi. org/10.1111/j.1365-2486.2011.02451.x

Kay, J. E., Deser, C., Phillips, A., Mai, A., Hannay, C., Strand, G., Arblaster, J. M., Bates, S. C., Danabasoglu, G., Edwards, J., Holland, M., Kushner, P., Lamarque, J.-F., Lawrence, D., Lindsay, K., Middleton, A., Munoz, E., Neale, R., Oleson, K., ... Vertenstein, M. (2015). The community earth system model (CESM) large ensemble project: A community resource for studying climate change in the presence of internal climate variability. Bulletin of the American Meteorological Society, 96, 1333-1349. https://doi.org/10.1175/BAMS-D-13-00255.1

King, A. D., Donat, M. G., Fischer, E. M., Hawkins, E. D., Alexander, L. V., Karoly, D. J., Dittus, A. J., Lewis, S. C., \& Perkins, S. E. (2015). The timing of anthropogenic emergence in simulated climate extremes. Environmental Research Letters, 10, 094015. https://doi.org/10.108 8/1748-9326/10/9/094015

Körner, C., \& Hiltbrunner, E. (2021). Why is the alpine flora comparatively robust against climatic warming? Diversity, 13, 383. https:// doi.org/10.3390/d13080383

Lande, R. (1998). Anthropogenic, ecological and genetic factors in extinction and conservation. Population Ecology, 40, 259-269. https:// doi.org/10.1007/BF02763457

Lande, R., Engen, S., \& Saether, B. (2003). Stochastic population dynamics in ecology and conservation. Oxford University Press.

Landrum, L., \& Holland, M. M. (2020). Extremes become routine in an emerging new arctic. Nature Climate Change, 10, 1108-1115. https://doi.org/10.1038/s41558-020-0892-z

Lemmer, J., Andrzejak, M., Compagnoni, A., Knight, T. M., \& Korell, L. (2021). Climate change and grassland management interactively influence the population dynamics of Bromus erectus (poaceae). 
Basic and Applied Ecology, 56, 226-238. https://doi.org/10.1016/j baae.2021.06.012

Lindström, J., \& Kokko, H. (2002). Cohort effects and population dynamics. Ecology Letters, 5, 338-344. https://doi. org/10.1046/j.1461-0248.2002.00317.x

Long, M. C., Deutsch, C., \& Ito, T. (2016). Finding forced trends in oceanic oxygen. Global Biogeochemical Cycles, 30, 381-397. https://doi. org/10.1002/2015GB005310

Lyu, K., Zhang, X., Church, J. A., Slangen, A. B., \& Hu, J. (2014). Time of emergence for regional sea-level change. Nature Climate Change, 4 , 1006-1010. https://doi.org/10.1038/nclimate2397

Mahlstein, I., Daniel, J. S., \& Solomon, S. (2013). Pace of shifts in climate regions increases with global temperature. Nature Climate Change, 3, 739-743. https://doi.org/10.1038/nclimate1876

Mahlstein, I., Hegerl, G., \& Solomon, S. (2012). Emerging local warming signals in observational data. Geophysical Research Letters, 39, n/a-n/a. https://doi.org/10.1029/2012gl053952

Mahlstein, I., Knutti, R., Solomon, S., \& Portmann, R. W. (2011). Early onset of significant local warming in low latitude countries. Environmental Research Letters, 6, 034009. https://doi.org/10.108 8/1748-9326/6/3/034009

Mann, M. E., Steinman, B. A., Brouillette, D. J., \& Miller, S. K. (2021). Multidecadal climate oscillations during the past millennium driven by volcanic forcing. Science, 371, 1014-1019. https://doi. org/10.1126/science.abc5810

Mantyka-pringle, C. S., Martin, T. G., \& Rhodes, J. R. (2012). Interactions between climate and habitat loss effects on biodiversity: A systematic review and meta-analysis. Global Change Biology, 18, 12391252. https://doi.org/10.1111/j.1365-2486.2011.02593.x

Mason, L. R., Green, R. E., Howard, C., Stephens, P. A., Willis, S. G. Aunins, A., Brotons, L., Chodkiewicz, T., Chylarecki, P., Escandell, V., Foppen, R. P. B., Herrando, S., Husby, M., Jiguet, F., Kålås, J. A., Lindström, Å., Massimino, D., Moshøj, C., Nellis, R., ... Gregory, R. D. (2019). Population responses of bird populations to climate change on two continents vary with species' ecological traits but not with direction of change in climate suitability. Climatic Change, 157, 337-354. https://doi.org/10.1007/s10584-01902549-9

Meinshausen, M., Smith, S. J., Calvin, K., Daniel, J. S., Kainuma, M. L. T., Lamarque, J.-F., Matsumoto, K., Montzka, S. A., Raper, S. C. B., Riahi, K., Thomson, A., Velders, G. J. M., \& van Vuuren, D. P. (2011). The RCP greenhouse gas concentrations and their extensions from 1765 to 2300. Climatic Change, 109, 213-241. https:// doi.org/10.1007/s10584-011-0156-z

Metcalf, J. C., Rose, K. E., \& Rees, M. (2003). Evolutionary demography of monocarpic perennials. Trends in Ecology \& Evolution, 18, 471-480. https://doi.org/10.1016/S0169-5347(03)00162-9

Mora, C., Frazier, A. G., Longman, R. J., Dacks, R. S., Walton, M. M., Tong, E. J., Sanchez, J. J., Kaiser, L. R., Stender, Y. O., Anderson, J. M., Ambrosino, C. M., Fernandez-Silva, I., Giuseffi, L. M., \& Giambelluca, T. W. (2013). The projected timing of climate departure from recent variability. Nature, 502, 183-187. https://doi.org/10.1038/natur e12540

Morris, W., Pfister, C., Tuljapurkar, S., Haridas, C. V., Boggs, C. L., Boyce, M. S., Bruna, E. M., Church, D. R., Coulson, T., Doak, D. F., Forsyth, S., Gaillard, J.-M., Horvitz, C. C., Kalisz, S., Kendall, B. E., Knight, T. M., Lee, C. T., \& Menges, E. S. (2008). Longevity can buffer plant and animal populations against changing climate variability. Ecology, 89, 19-25.

Mustin, K., Dytham, C., Benton, T. G., \& Travis, J. M. J. (2013). Red noise increases extinction risk during rapid climate change. Diversity and Distributions, 19, 815-824. https://doi.org/10.1111/ ddi.12038

Neubert, M., \& Caswell, H. (2000). Density-dependent vital rates and their population dynamic consequences. Journal of Mathematical Biology, 41, 103-121. https://doi.org/10.1007/s002850070001
Oli, M. K. (2004). The fast-slow continuum and mammalian life-history patterns: An empirical evaluation. Basic and Applied Ecology, 5, 449463. https://doi.org/10.1016/j.baae.2004.06.002

O'Neill, B. C., Tebaldi, C., van Vuuren, D. P., Eyring, V., Friedlingstein, P., Hurtt, G., Knutti, R., Kriegler, E., Lamarque, J.-F., Lowe, J., Meehl, G. A., Moss, R., Riahi, K., \& Sanderson, B. M. (2016). The scenario model intercomparison project (ScenarioMIP) for CMIP6. Geoscientific Model Development, 9, 3461-3482. https://doi. org/10.5194/gmd-9-3461-2016

Ozgul, A., Childs, D. Z., Oli, M. K., Armitage, K. B., Blumstein, D. T., Olson, L. E., Tuljapurkar, S., \& Coulson, T. (2010). Coupled dynamics of body mass and population growth in response to environmental change. Nature, 466, 482. https://doi.org/10.1038/ nature09210

Paniw, M., Ozgul, A., \& Salguero-Gómez, R. (2017). Interactive lifehistory traits predict sensitivity of plants and animals to temporal autocorrelation. Ecology Letters, 21, 275-286. https://doi. org/10.1111/ele.12892

Parmesan, C., Burrows, M. T., Duarte, C. M., Poloczanska, E. S., Richardson, A. J., Schoeman, D. S., \& Singer, M. C. (2013). Beyond climate change attribution in conservation and ecological research. Ecology Letters, 16, 58-71. https://doi.org/10.1111/ele.12098

Peñuelas, J., \& Munné-Bosch, S. (2010). Potentially immortal? The New Phytologist, 187, 564-567. https://doi. org/10.1111/j.1469-8137.2010.03360.x

Radchuk, V., Turlure, C., \& Schtickzelle, N. (2013). Each life stage matters: The importance of assessing the response to climate change over the complete life cycle in butterflies. Journal of Animal Ecology, 82, 275-285. https://doi.org/10.1111/j.1365-2656.2012.02029.x

Ranta, E., Lundberg, P., \& Kaitala, V. (2005). Ecology of populations. Cambridge University Press.

Reed, P. B., Bridgham, S. D., Pfeifer-Meister, L. E., DeMarche, M. L., Johnson, B. R., Roy, B. A., Bailes, G. T., Nelson, A. A., Morris, W. F., $\&$ Doak, D. F. (2021). Climate warming threatens the persistence of a community of disturbance-adapted native annual plants. Ecology, 102, e03464. https://doi.org/10.1002/ecy.3464

Rescan, M., Grulois, D., Ortega-Aboud, E., \& Chevin, L. M. (2020). Phenotypic memory drives population growth and extinction risk in a noisy environment. Nature Ecology \& Evolution, 4, 193-201. https://doi.org/10.1038/s41559-019-1089-6

Revelle, R., \& Suess, H. E. (1957). Carbon dioxide exchange between atmosphere and ocean and the question of an increase of atmospheric $\mathrm{CO}_{2}$ during the past decades. Tellus, 9, 18-27. https://doi. org/10.3402/tellusa.v9i1.9075

Rojas, M., Lambert, F., Ramirez-Villegas, J., \& Challinor, A. J. (2019). Emergence of robust precipitation changes across crop production areas in the 21st century. Proceedings of the National Academy of Sciences of the United States of America, 116, 6673-6678. https:// doi.org/10.1073/pnas.1811463116

Román-Palacios, C., \& Wiens, J. J. (2020). Recent responses to climate change reveal the drivers of species extinction and survival. Proceedings of the National Academy of Sciences of the United States of America, 117, 4211-4217. https://doi.org/10.1073/pnas.19130 07117

Roth, G., \& Caswell, H. (2018). Occupancy time in sets of states for demographic models. Theoretical Population Biology, 62-77. https:// doi.org/10.1016/j.tpb.2017.12.007

Saether, B., \& Bakke, O. (2000). Avian life history variation and contribution of demographic trait to the population growth rate. Ecology, 81, 642-653.

Sæther, B. E., \& Engen, S. (2015). The concept of fitness in fluctuating environments. Trends in Ecology \& Evolution, 30, 273-281. https:// doi.org/10.1016/j.tree.2015.03.007

Sæther, B.-E., Engen, S., Gamelon, M., \& Grøtan, V. (2019). Predicting the effects of climate change on bird population dynamics. In P. O. Dunn \& A. P. Møller (Eds.), Effects of climate change on birds (2nd 
ed., pp. 74-90). Oxford University Press. https://doi.org/10.1093/ oso/9780198824268.003.0007

Sæther, B. E., Lillegard, M., Grøtan, V., Filli, F., \& Engen, S. (2007). Predicting fluctuations of reintroduced ibex populations: The importance of density dependence, environmental stochasticity and uncertain population estimates. Journal of Animal Ecology, 76, 326-336. https://doi.org/10.1111/j.1365-2656.2006.01197.x

Sæther, B.-E., \& Saether, B.-E. (1987). The influence of body weight on the covariation between reproductive traits in European birds. Oikos, 79-88. https://doi.org/10.2307/3565691

Sæther, B. E., Sutherland, W. J., \& Engen, S. (2004). Climate influences on avian population dynamics. Advances in Ecological Research, 35, 185-209.

Salguero-Gómez, R., Jones, O. R., Jongejans, E., Blomberg, S. P., Hodgson, D. J., Mbeau-Ache, C., Zuidema, P. A., de Kroon, H., \& Buckley, Y. M. (2016). Fast-slow continuum and reproductive strategies structure plant life-history variation worldwide. Proceedings of the National Academy of Sciences of the United States of America, 113, 230-235. https://doi.org/10.1073/pnas.1506215112

Schlunegger, S., Rodgers, K. B., Sarmiento, J. L., Ilyina, T., Dunne, J. P., Takano, Y., Christian, J. R., Long, M. C., Frölicher, T. L., Slater, R., \& Lehner, F. (2020). Time of emergence and large ensemble intercomparison for ocean biogeochemical trends. Global Biogeochemical Cycles, 34. https://doi.org/10.1029/2019gb006453

Schwager, M., Johst, K., \& Jeltsch, F. (2006). Does red noise increase or decrease extinction risk? Single extreme events versus series of unfavorable conditions. The American Naturalist, 167, 879-888. https://doi.org/10.1086/503609

Schwalm, C. R., Glendon, S., \& Duffy, P. B. (2020). Rcp8. 5 tracks cumulative $\mathrm{CO}_{2}$ emissions. Proceedings of the National Academy of Sciences of the United States of America, 117, 19656-19657.

Sorte, F. A. L., Fink, D., \& Johnston, A. (2019). Time of emergence of novel climates for North American migratory bird populations. Ecography, 42, 1079-1091. https://doi.org/10.1111/ecog.04408

Stearns, S. C. (1983). The influence of size and phylogeny on patterns of covariation among life-history traits in the mammals. Oikos, 173187. https://doi.org/10.2307/3544261

Steinger, T., Körner, C., \& Schmid, B. (1996). Long-term persistence in a changing climate: DNA analysis suggests very old ages of clones of alpine Carex curvula. Oecologia, 105, 94-99. https://doi. org/10.1007/BF00328796

Stephens, P. A., Mason, L. R., Green, R. E., Gregory, R. D., Sauer, J. R., Alison, J., Aunins, A., Brotons, L., Butchart, S. H. M., Campedelli, T., Chodkiewicz, T., Chylarecki, P., Crowe, O., Elts, J., Escandell, V., Foppen, R. P. B., Heldbjerg, H., Herrando, S., Husby, M., ... Willis, S. G. (2016). Consistent response of bird populations to climate change on two continents. Science, 352, 84-87. https://doi. org/10.1126/science.aac4858

Szostek, K. L., \& Becker, P. H. (2015). Survival and local recruitment are driven by environmental carry-over effects from the wintering area in a migratory seabird. Oecologia, 178, 643-657.
Trathan, P. N., Wienecke, B., Barbraud, C., Jenouvrier, S., Kooyman, G., Le Bohec, C., Ainley, D. G., Ancel, A., Zitterbart, D. P., Chown, S. L., LaRue, M., Cristofari, R., Younger, J., Clucas, G., Bost, C.-A., Brown, J. A., Gillett, H. J., \& Fretwell, P. T. (2020). The emperor penguin-vulnerable to projected rates of warming and sea ice loss. Biological Conservation, 241, 108216. https://doi.org/10.1016/j. biocon.2019.108216

Treurnicht, M., Pagel, J., Esler, K. J., Schutte-Vlok, A. L., Nottebrock, H., Kraaij, T., Rebelo, A. G., \& Schurr, F. M. (2016). Environmental drivers of demographic variation across the global geographical range of 26 plant species. Journal of Ecology, 104, 331-342. https://doi. org/10.1111/1365-2745.12508

Tuljapurkar, S. D. (1982). Population dynamics in variable environments. III. Evolutionary dynamics of $r$-selection. Theoretical Population Biology, 21, 141-165.

Tuljapurkar, S., Gaillard, J. M., \& Coulson, T. (2009). From stochastic environments to life histories and back. Philosophical Transactions of the Royal Society B: Biological Sciences, 364, 1499-1509. https://doi. org/10.1098/rstb.2009.0021

Tuljapurkar, S., \& Orzack, S. (1980). Population dynamics in variable environments I. Long-run growth rates and extinction. Theoretical Population Biology, 18, 314-342.

Vázquez, D. P., Gianoli, E., Morris, W. F., \& Bozinovic, F. (2015). Ecological and evolutionary impacts of changing climatic variability. Biological Reviews, 92, 22-42. https://doi.org/10.1111/brv.12216

Zappa, G., Hoskins, B. J., \& Shepherd, T. G. (2015). Improving climate change detection through optimal seasonal averaging: The case of the north Atlantic jet and European precipitation. Journal of Climate, 28, 6381-6397. https://doi.org/10.1175/ JCLI-D-14-00823.1

Zimmermann, N. E., Yoccoz, N. G., Edwards, T. C., Meier, E. S., Thuiller, W., Guisan, A., Schmatz, D. R., \& Pearman, P. B. (2009). Climatic extremes improve predictions of spatial patterns of tree species. Proceedings of the National Academy of Sciences of the United States of America, 106, 19723-19728. https://doi.org/10.1073/ pnas.0901643106

\section{SUPPORTING INFORMATION}

Additional supporting information may be found in the online version of the article at the publisher's website.

How to cite this article: Jenouvrier, S., Long, M. C., Coste, C. F. D., Holland, M., Gamelon, M., Yoccoz, N. G., \& Sæther, B.-E. (2022). Detecting climate signals in populations across life histories. Global Change Biology, 00, 1-23. https://doi. org/10.1111/gcb.16041 